ISSN: 0213-2079 - ISSN electrónico: 2386-3889

DOI: https://doi.org/10.14201/shhmo2016382201236

\title{
CRISIS FAMILIARES Y MIGRACIONES EN LA GALICIA DEL SIGLO XVIII DESDE UNA PERSPECTIVA DE GÉNERO*
}

\section{Family Crises and Migrations in Eighteenth-Century Galicia from a Gender Perspective}

\author{
Ofelia REY CASTELAO \\ Universidad de Santiago de Compostela \\ Correo-e: ofelia.rey@usc.es
}

RESUMEN: Este artículo estudia el problema de la relación entre crisis y migraciones desde el punto de vista de las mujeres. Esta reflexión se hace utilizando la información disponible para Galicia en el siglo XvIII; este territorio se caracterizaba por una intensa emigración masculina, con dos variantes: la migración estacional o de corta duración a Castilla y la polianual o de media duración a Portugal y Andalucía. Para estudiar su impacto sobre las mujeres, este trabajo se divide en dos partes: a) en la primera se observan las crisis familiares que ocasionaba la muerte del marido ausente o su abandono voluntario de la familia, y se plantean las soluciones posibles; b) en la segunda, la atención se centra en las mujeres solteras que se vieron en la necesidad de emigrar para resolver sus crisis personales, es decir, aquellos momentos en los que ellas tuvieron que tomar una decisión para resolver su propio futuro.

Palabras clave: crisis familiares; migraciones; Galicia; mujeres; siglo XVIII.

ABSTRACT: This paper studies the problem of the relationship between crisis and migrations from the women's point of view. This reflection is done

* El tema se enmarca en el proyecto Culturas urbanas: las ciudades interiores en el Noroeste Ibérico. Dinámicas e impacto en el espacio rural, HaAR2015-64014-C3-3-R, MINECO.

(C) Ediciones Universidad de Salamanca / ®@ Stud. his., H. ${ }^{a}$ mod., 38, n. 2 (2016), pp. 201-236 
OFELIA REY CASTELAO

CRISIS FAMILIARES Y MIGRACIONES EN LA GALICIA DEL SIGLO XVIII DESDE UNA PERSPECTIVA DE GÉNERO

using the information available to Galicia in the $18^{\text {th }}$ Century. This territory was characterized by intense male migration, with two variants: seasonal or short-term migration to Castile and the multiyear or medium-term to Portugal and Andalusia. In order to study its impact on women, this paper is divided into two parts: a) firstly, the focus is on family crisis that caused whether the death of the absentee husband or the voluntary abandonment of the family, and proposing the different choices; b) secondly, the aim is to study those single women who were in the need to migrate in order to solve their personal crisis, that is to say, those times when they had to make a decision to solve their own future.

Keywords: Family Crises; Migrations; Galicia; Women; 18th Century.

\section{INTRODUCCIÓN}

Nuestro grado de conocimiento sobre la movilidad y las migraciones en la Galicia moderna es sin duda muy elevado, pero esto no impide que muchas preguntas sigan abiertas o sin respuestas convincentes ${ }^{1}$. La que se nos ha propuesto es precisamente una de esas cuestiones y es quizá también una de las de más difícil resolución. En primer lugar porque, historiográficamente, el concepto de «crisis familiar» no está bien definido o lo está solo de modo impreciso, vinculándolo con la muerte de un componente de la familia, la separación de la pareja nuclear, o una situación sobrevenida -invalidez, paro-. En lo segundo porque no está clara la relación entre ese tipo de crisis y la migración; recientemente Tania Kaiser la puso en duda recordando que muchas migraciones eran forzadas o semi-libres, con independencia de que sus protagonistas fueran o no conscientes de ello ${ }^{2}$. Por otra parte, se puede dar la vuelta al título, ya que la emigración por sí misma podía generar crisis familiares. Sin ir más lejos, una gran parte de las ausencias que se clasifican como definitivas fueron, en realidad, ausencias temporales sin retorno por muerte o por voluntad de sus protagonistas; se conocieran o no esas circunstancias, provocaban en las familias situaciones problemáticas si el ausente era imprescindible para la obtención de recursos, o de vacío legal si era un hijo o una hija cuyos padres se veían obligados a alterar la sucesión hereditaria o a dejar previsto su regreso. Las ausencias de maridos y de componentes masculinos en

1. Rey Castelao, O.: «Las migraciones de los rurales en el siglo XviII: cuestiones pendientes», Minius, Historia, Arte e Xeografía, 20, 2012, pp. 119-156.

2. KAISER, T.: «crisis? Wich crisis? Families and Forced Migration», en Lindley, A. (Ed.): Crisis and Migration: Cultural Perspectives. Nueva York, 2014, s. p.

(C) Ediciones Universidad de Salamanca / ®@ Stud. his., H. ${ }^{a}$ mod., 38, n. 2 (2016), pp. 201-236 
edad laboral podían dar lugar a situaciones de estrés si la migración resultaba poco productiva y el emigrante no enviaba remesas de dinero o desarticulaba la economía doméstica, aunque, paradójicamente, precisamente porque tenían que asumir un rol de mando, las mujeres de ausentes rompen el estereotipo de las «dependientes pasivas», como veremos.

Sea válido o no para la Edad Moderna, el concepto de «crisis familiar» provoca un problema de método, el de su identificación, localización y datación, y un problema no menor, el del tipo de fuentes necesario, que debería aportar información ya no suficiente, sino expresiva. Pero los asuntos personales y particulares -las crisis familiares lo son- se planteaban y solucionaban sin trascender en la documentación, salvo cuando se explicaron en textos privados o derivaron en una situación excepcional o en un conflicto llevado ante notario o ante un tribunal. Estos problemas se agravan en lo referente a las mujeres, sector en el que centraremos estas páginas, no tanto por su invisibilidad documental, que es relativa, como por la complejidad y diversidad de los datos, difícilmente comparables y cuantificables al proceder de fuentes diferentes entre sí que aportan información de aspectos dispares o incluso contradictorios.

En una Galicia mayoritariamente analfabeta, no es sorprendente que no hayamos encontrado relatos referidos a los sectores femeninos desfavorecidos, rurales o urbanos, que hubieran podido ayudarnos a identificar las situaciones de crisis y sus posibles soluciones. Así pues, las únicas fuentes narrativas que permiten penetrar en el ámbito privado son las escrituras notariales, sin que puedan segregarse las más adecuadas, ya que cada tipo puede ofrecer pistas o indicios, y sin que puedan cuantificarse, aunque, al menos, de la repetición de lo circunstancial y episódico se deducen líneas de comportamiento. La otra documentación que puede colaborar en esto es la judicial, tanto civil como criminal, donde hemos hallado algunas noticias, pero tampoco son medibles y se refieren más bien a los efectos que sobre las mujeres tuvo la emigración de los hombres. Precisamente por esto, emplearemos ese tipo de información en la primera parte de este trabajo, destinada a plantear los problemas que tuvieron que afrontar las esposas de ausentes y sus familias.

En la segunda parte, donde se aborda la cuestión de las mujeres que se vieron en la necesidad de emigrar, la información empleada en la bibliografía que nos sirve de base, procede de fuentes clásicas de los estudios migratorios ${ }^{3}$. Debemos tener en cuenta que en lo referente a las mujeres, a diferencia de los hombres, los

3. Rey Castelao, O.: «Migraciones internas y medium-distance en Galicia, siglos XVI-XIX», en Eiras Roel, A. y Rey Castelao, O. (Eds.): Migraciones internas y medium distance en la Península Ibérica, 1500-1900. Santiago de Compostela, 1994, pp. 85-130.

(C) Ediciones Universidad de Salamanca / ®@ Stud. his., H. ${ }^{a}$ mod., 38, n. 2 (2016), pp. 201-236 
registros parroquiales de los lugares de origen fallan estrepitosamente, salvo rara excepción; así, mientras era normal que en las actas matrimoniales se registrasen las ausencias prematrimoniales de los novios, no suelen aparecer las protagonizadas por las novias, quizá porque habrían sido a lugares cercanos en los que la familia y la comunidad tendrían información permanente sobre ellas, no en vano las anotaciones referidas a ellos solo tenían como finalidad evitar los casos de bigamia o de demandas por palabra de matrimonio, más fáciles cuanto más lejos y más tiempo hubieran estado ausentes. En Galicia han dado mucho juego los registros de «muertos fuera», hasta el punto de que han permitido reconstruir la evolución de las migraciones y cartografiar sus destinos; pero pocas veces se han localizado anotaciones referidas a mujeres, quizá porque al tratarse de solteras o viudas que no volvieron a sus aldeas, los vínculos familiares se habrían debilitado. En los recuentos de población del XVIII sucede lo mismo, aunque también reflejan mal las ausencias masculinas, ya que para los objetivos fiscales que perseguían los de 1708/9 y 1753, interesaba la unidad fiscal, no su titularidad; en los censos de Carlos III la información no es mejor, porque oculta el número de casados ausentes. La documentación militar ha servido para medir la emigración masculina, pero no existe para las mujeres, evidentemente. Así pues, la documentación de las zonas de salida ha servido sobre todo para observar los efectos de la movilidad sobre la población femenina, pero mucho menos para detectar la movilidad femenina.

En cuanto a la documentación de las zonas de llegada, el desequilibrio entre hombres y mujeres no es tan acusado. Las mujeres aparecen en los registros parroquiales, casándose o teniendo hijos; este doble control se hizo con éxito para varias ciudades gallegas, como veremos, lo que ha permitido identificar a los solteros/as y viudos/as inmigrados que se hubieran casado en allí y a las parejas que habían llegado casadas; a veces aparecen los hijos de solteras foráneas, si bien podían ser estancias pasajeras destinas a ocultar un embarazo ilegítimo. Los registros hospitalarios han sido también una fuente común a los dos sexos, pero no del todo equilibrada, ya que el número de salas femeninas solía ser menor que el de salas masculinas.

El problema más grave de los desequilibrios informativos radica en que solo permiten ver una parte de la movilidad femenina, sin que podamos aproximarnos a su dimensión real y menos a su evolución. Por otra parte, la documentación aporta datos sesgados de las mujeres, al captarlas en momentos diferentes del ciclo vital y en muy diferentes circunstancias: las mujeres solteras, jóvenes y sanas que hubieran hecho un desplazamiento temporal y que hubieran retornado sin cambiar de estado, sin haber suscrito un contrato o incurrido en conflicto, se escapan a todo control; sucede lo mismo con los varones, pero la documentación militar o la fiscal acaba por localizarlos en algún momento.

(C) Ediciones Universidad de Salamanca / ®@ Stud. his., H. ${ }^{a}$ mod., 38, n. 2 (2016), pp. 201-236 
En las páginas que siguen nos centraremos en el siglo XviII, tanto por una mayor disponibilidad de datos, como porque es un siglo sin grandes crisis colectivas, salvo las de 1709/1710 y 1769/1770, lo que nos permitirá focalizar la atención en las crisis familiares. Para la Galicia occidental, la mejor informada y más asidua en nuestras referencias, fue un siglo de relativo estancamiento económico, después de un fuerte crecimiento en el XviI, a causa de la esclerosis agrícola y de la superpoblación, cuyo resultado fue una intensa emigración masculina, única solución en ausencia de una economía urbana y moderna ${ }^{4}$. A título particular y privado, las crisis más habituales, por su repetición generacional, fueron sin duda las que seguían a la muerte de los padres y obligaban a pagar los gastos de funeración y a repartir explotaciones agrarias que eran en general muy pequeñas, hasta hacerlas inviables en muchos casos. Igual de recurrentes eran las derivadas del endeudamiento crónico, que en un momento dado podían comportar un embargo de bienes e incluso en la cárcel. Las familias resistían en un sistema de estricta supervivencia, gracias a que la tierra que trabajaban era de su propiedad o la tenían en régimen de usufructo largo, a que disponían de ganado y aperos, y de espacios de monte o de tierra inculta de explotación vecinal, y a que desarrollaron la producción textil, muy extendida en Galicia en la segunda mitad del xviII.

Pero la insuficiencia casi permanente obligó a que tuvieran que emigrar uno o varios componentes, hombres en su mayoría, pero también bastantes mujeres, para asegurar la subsistencia del grupo doméstico. Es lo que, desde la frialdad de la demografía histórica, se ha denominado «disminución selectiva del tamaño de las familias» ${ }^{5}$, pero que desde la perspectiva social refleja situaciones de estrés o de crisis de los que solo conocemos los síntomas y apenas sus soluciones. No entraremos en los efectos generales de la emigración masculina, sino de la emigración de hombres casados, que pueden sintetizarse en el alivio parcial de las deficiencias económicas de sus casas mediante un dinero que se destinaba a pagar impuestos, rentas, aperos, deudas, dotes de hijas. Lo que nos interesa ver es cuándo fallaban esas previsiones y el alivio no llegaba, y las posibilidades de acción y reacción de las mujeres de los ausentes.

Por otra parte, nos interesan las mujeres que emigraron y buscaron por sí mismas la solución a sus propios problemas de insuficiencia, en especial solteras adultas y viudas, con o sin hijos, que habían heredado pequeñas explotaciones y que buscaban

4 Eiras Roel, A.: Estudios sobre agricultura y población en la España Moderna. Santiago de Compostela, 1990.

5. Poussou, J. P.: «La familia y los movimientos migratorios en Francia», en CHAcon JimeneZ, F. (ed.): Familia y sociedad en el Mediterráneo occidental, siglos XV-XIX. Murcia, 1987, pp. 121 y ss.

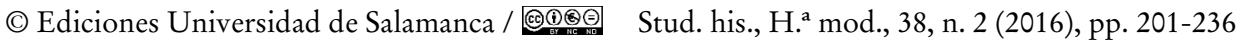


OFELIA REY CASTELAO

CRISIS FAMILIARES Y MIGRACIONES EN LA GALICIA DEL SIGLO XVIII DESDE UNA PERSPECTIVA DE GÉNERO

ingresos complementarios, a pesar de que las fuentes disponibles no permiten distinguirlas de las que emigraban por razones menos urgentes, como formar una dote o colocar en el mercado los productos de la actividad textil. No tendremos en cuenta la micro-movilidad por matrimonio, bien conocida en Galicia, ni en la cake-mobility, es decir, la de las mujeres de clases acomodadas, porque no responden al problema general de estas páginas, ni la emigración a América, que en el xviII apenas incluyó a mujeres, sino que intentaremos perfilar el modelo de movilidad de las gallegas e indagar sus causas. Se trata, por lo tanto, de ver las dos caras de la emigración.

\section{Mujeres Frente A LA AUSENCIA}

En un territorio como el gallego, caracterizado por su enorme emigración masculina, la ausencia de los hombres casados tenía como objetivo sostener a la familia en su ciclo inicial de reproducción, y paliar las deficiencias de las economías particulares, aportando un dinero que era esencial para pagar impuestos, rentas o aperos, o para cubrir una situación de endeudamiento, cuando no huyeron de sus acreedores. Si lo conseguían, podían resolver una crisis, pero si fracasaban, si no mandaban remesas, si no volvían voluntariamente o si morían en sus destinos, ponían a sus mujeres e hijos en peor situación que la de origen. Entre los solteros las motivaciones para la partida podían ser otras -eludir servicios militares, reunir dinero para casarse, buscar nuevas perspectivas-, y las consecuencias de su emigración eran diferentes, por lo que nos ocuparemos de las mujeres casadas y de los problemas que les creaban las ausencias de sus maridos, el desconocimiento de su paradero o su muerte fuera de casa. Es una cuestión que está siendo objeto de innovadores estudios en Francia y Canadá ${ }^{6}$, por cuanto ha sido oscurecida por el interés historiográfico otorgado a la viudez y a la soltería definitiva. En efecto, lo que preocupa en los últimos años son circunstancias y condiciones en que se quedaban esas mujeres y cuál era la repercusión de las ausencias de ellos en sus vidas cotidianas, hasta qué punto estas se modificaban, y cómo se producía el retorno de los maridos y la reposición de la situación previa. No obstante, conviene decir que en Galicia tenemos ya bastante bibliografía sobre esta otra dimensión, no en vano una buena parte de la emigración masculina fue protagonizada por hombres casados ${ }^{7}$.

6. Grenier, B. y E. Charpentier, E. (Eds.): Femmes Face à L'absence, Bretagne et Québec (xviIe-Xvilie Siècles). Québec, 2015.

7. Rey Castelao, O.: «Les femmes seules du Nord-Ouest de l'Espagne: trajectoires féminines dans un territoire d'émigration, 1700-1860», Annales de démographie historique, 112, 2006, pp. 13-30.

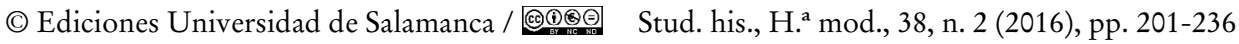


No es fácil generalizar la situación de las mujeres casadas cuyos maridos emigraron en un momento dado, porque era muy amplio el abanico de posibilidades, dependiendo de las causas de la ausencia -actividad marinera, laboral, militar-, de sus modalidades -elegida, impuesta, semi-libre-, del lugar de destino-ciudades, campo, costa, montaña, colonias-, y sobre todo de la duración, dadas las importantes diferencias entre la movilidad de ciclo corto, en sus variantes de emigración estacional agrícola, la artesanal de oficios y la de tráfico ambulante, la de ciclo medio o poli-anual, y la de carácter definitivo, ya fuese voluntario o sobrevenido. Igual de determinantes eran la edad de las mujeres, la existencia y número de hijos e hijas, el medio socio-económico de la familia, y las eventuales ayudas por parte de parientes y vecinos. Los efectos de las ausencias masculinas se hacían sentir sobre las comunidades dependiendo del número de individuos emigrados y obedecían a dinámicas más o menos estables y en general bien conocidas, pero no así las implicaciones en la dimensión personal, en el seno de la pareja y de las familias, por lo que interesa saber si las mujeres inmersas en esas instituciones eran víctimas de la separación o, por el contrario, si adquirían autonomía o independencia, y cómo la gestionaban. En teoría, en una sociedad en la que el encuadramiento se producía mediante el matrimonio, las ausencias repetidas y/o duraderas de los maridos dejaban a sus esposas en una situación indefinida o intermedia que las diferenciaba de las viudas o de las solteras adultas. Las viudas se beneficiaban de una capacidad jurídica plena para administrar sus bienes y los gananciales, pero las «viudas de vivos» en territorios de familia nuclear, se distinguían en que mientras ellos estaban fuera asumían la condición de cabezas de familia y todas las obligaciones de esta, y en que cuando ellos regresaban, recuperaban su papel, de forma que esas mujeres vivían una existencia bipolar. Esto plantea varias dimensiones: el estatuto jurídico en el que quedaban las mujeres, las consecuencias económicas de la ausencia y las estrategias para afrontarla -diversidad de prácticas individuales y de la familia, repartición de tareas en la pareja, trabajo femenino, solidaridades femeninas, familiares y parroquiales, etc.- y el impacto de la ausencia sobre el matrimonio y la familia en lo referente a las relaciones de poder, las responsabilidades familiares, el lugar de las mujeres en los asuntos del hogar-capacidad de acción, relaciones de confianza, formación y educación-, el papel de los otros miembros de la familia -padres, hermanos, cuñados- y la reorganización de los ritmos cotidianos, facetas que en Galicia están bien estudiadas, por lo que nos centraremos solo en más críticas.

Cuando los campesinos se iban a la siega a Castilla, cuando los canteros de Tierra de Montes y Cotobade, los mamposteros del sudeste tudense, los sogueros ourensanos o los buhoneros de la depresión de Maceda y el valle del Sil, se desplazaban fuera de Galicia para ejercer sus oficios, o cuando el éxodo estacional

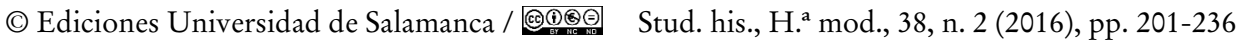


OFELIA REY CASTELAO

se convertía en temporal o en definitivo, las mujeres eran las que permanecían al frente de la familia. La emigración de solteros era mayoritaria, pero en la Galicia atlántica fue muy intensa la emigración de hombres casados con destinos en Castilla, Andalucía o Portugal; esto significaba ausencias polianuales, lo que se hizo sentir con fuerza en numerosas localidades y comarcas: en la provincia de Santiago en 1708 estaban casados el 45,6\% de los ausentes, casi todos cabezas de familia; cifra similar se obtiene en las penínsulas de Salnés y de Morrazo a lo largo del siglo XVIII, en la cuenca baja del Ulla, en la zona fronteriza con Portugal o en Tierra de Montes ${ }^{8}$.

El problema fundamental era el de los hombres casados que morían fuera, ya que generaban una verdadera crisis familiar, tanto por las consecuencias económicas de la muerte, como por los problemas legales de gestión de su herencia, en especial cuando precedía un período de desconocimiento de su paradero o cuando no había un testamento o una disposición escrita o verbal ante testitos. En las áreas sudoccidentales de Galicia este problema alcanzó una notable importancia. Debe tenerse en cuenta que solo en las actas de defunción de las parroquias de partida, donde se asentaban los actos fúnebres en memoria de los ausentes, las cifras son impactantes en su conjunto, pero solo reflejan a una parte de los fallecidos, aquellos de los que llegó a saberse su muerte, lo que seguramente tenía mucho que ver con la mayor o menor lejanía de los destinos y con la duración de la ausencia; además de esto, las partidas no siempre dan el estado civil de los difuntos ausentes. En Tierra de Montes, zona de emigración de canteros y profesionales de la construcción, donde la emigración masculina obedecía a esa circunstancia laboral, en el siglo XVIII estaban casados el 19,4\% de los muertos fuera, en destinos muy diversos como correspondía a ese tipo de movilidad, si bien en su mayoría en Castilla; en este caso, dado que los hombres viajaban frecuentemente en cuadrillas organizadas en función de las contratas, se puede suponer que la información sobre las muertes de compañeros llegaba mejor a sus familias; en todo caso, el 26,2\% de las partidas no da el estado civil de los fallecidos, de los que seguramente algunos estarían casados también 9 . En una zona próxima y con algunos caracteres parecidos, los casados eran el 11,6\% de aquellos de los que figura su condición en la primera

8. Eiras Roel, A.: «Para una comarcalización del estudio de la emigración gallega. La diversificación intrarregional a través de los censos de población», en EIRAs Roel, A. (Ed.): Aportaciones al estudio de la emigración gallega. Un enfoque comarcal. Santiago de Compostela, 1992, pp. 7-32.

9. Fernandez Cortizo, C. J.: «Emigración peninsular y americana en Tierra de Montes (1700-1914», Revista Galega do V Centenario, 7, 1989, pp. 167-183; «Trabajar por sus oficios fuera del Reino. El éxodo estacional en la Tierra de Montes, siglos XVII-XIX», en EIras Roel, A. (Ed.): Aportaciones al estudio, op. cit., pp. 45-65.

(C) Ediciones Universidad de Salamanca / ®@ Stud. his., H. ${ }^{a}$ mod., 38, n. 2 (2016), pp. 201-236 
mitad del XVIII y el 31,2\% en la segunda, pero la falta de referencia al estado civil es del $49,5 \%$ en el primer tramo y del $37,6 \%$ en el otro $^{10}$. En la zona de A Cañiza, muy próxima a Portugal, estaban casados el 8,5\% de los muertos en Castilla en la primera mitad del XVIII y el 15,3\% en la segunda, y el $11,7 \%$ y $19 \%$ respectivamente murieron en Portugal: en total 112 hombres, de los que 84 fallecieron en este país y 28 en Castilla, pero además algunos murieron en Andalucía y en destinos que no se anotaron, e ignoramos el estado civil del 38,5\% de los muertos en Castilla en $1700-1749$ y el $19,4 \%$ después, y del $30,5 \%$ y $26,5 \%$ respectivamente de los emigrados a tierras andaluzas ${ }^{11}$. En once feligresías del Bajo Miño, entre $1691 \mathrm{y}$ 1850, lo estaba el 50,7\% de los emigrados a Castilla -925 hombres-, 26,9\% de los muertos en Andalucía (158 casos) y 27,3\% en Portugal -solo 57 partidas-; en el estudio de José Manuel Pérez García sobre esa zona, se subraya que no consta el estado civil del $12,7 \%$ en el primer caso, el $20,3 \%$ en el segundo y el $16,3 \%$ en el tercero, por lo que el número de casados ausentes sería mayor ${ }^{12}$. Debe tenerse en cuenta que el número de actas de defunción masculinas, en las mismas parroquias donde se anotaron los actos por difuntos fuera, son muy inferiores en número a las femeninas, de modo que un porcentaje muy variable corresponde a aquellos ausentes que nunca volvieron y de los que nada se sabía y aunque es de suponer que fuesen solteros en su mayoría, otros serían casados y habría que contarlos a mayores. De hecho, en las zonas de emigración polianual, el porcentaje de viudas menores de cuarenta años es superior al de las zonas de emigración masculina estacional o sin emigración, dado que las posibilidades de sobre-mortalidad masculina propiciada por la emigración -accidentes, contagios- eran más elevadas cuanto más prolongada fuera la ausencia.

Los visitantes foráneos, los ilustrados y observadores gallegos -los benedictinos Feijoo y Sarmiento- y los locales, el gobierno de Madrid -en especial Rodríguez de Campomanes- y las autoridades regnícolas, no fueron unánimes al valorar la importancia económica de las remesas de dinero que los maridos pudieran traer de sus desplazamientos, pero sí sobre la consecuencias negativas que las ausencias masculinas generaban en las explotaciones agrarias y en las economías, no en vano la mayoría de ellos pertenecían a las clases propietarias que pensaban en sus rentas

10. González Lopo, D. L.: «Una aproximación a la emigración de la Galicia occidental. Entre mediados del siglo XVIII y el primer tercio del siglo xx a través de las fuentes de protocolos y actas parroquiales», Revista galega do V Centenario, 6, pp. 133-170.

11. Rey Castelao, O. y Pérez Rodríguez, F.: «Movimientos migratorios en el municipio de A Cañiza, siglos XVII al XIX», en Eiras Roel, A. (Ed.): Aportaciones al estudio, op. cit., pp. 33-44.

12. Pérez García, J. M.: «La intensa movilidad de la comarca del Bajo Miño y sus destinos», Minius. Historia, Arte e Xeografía, 19, 2011, pp. 231-254.

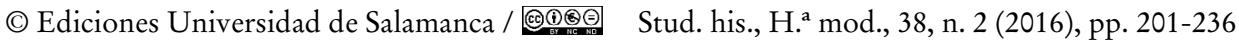


OFELIA REY CASTELAO

CRISIS FAMILIARES Y MIGRACIONES EN LA GALICIA DEL SIGLO XVIII DESDE UNA PERSPECTIVA DE GÉNERO

y en los jornales que tenían que pagar. Pero también fueron sensibles a la carga de trabajo que las mujeres asumían ${ }^{13}$, con independencia de la distancia a la que estuvieran sus maridos. Así por ejemplo, el corregidor de Ferrol don Fernando Vivero Calderón lamentaba el abandono de las tareas agrícolas en el entorno de esa ciudad, porque «aunque en toda Galicia se travaxa mal el campo, en el contorno de esta villa se hace peor que en otra parte alguna; esto nace del jornal que hallan en las Reales Obras de este Departamento, a donde se vienen dexando sus haciendas encargadas a las mugeres» y el clérigo P. González de Ulloa, al referirse a comarcas centrales de Ourense, escribía en 1771 que «los más de sus naturales son trashumantes a Extremadura, Portugal y otras partes con el oficio de sogueros y buhoneros, dejando el cuidado de la familia y de la agricultura a sus esclavas mujeres» ${ }^{14}$.

La literatura de la época, tanto española -más bien, la madrileña- como portuguesa, insinuaba que las mujeres de ausentes solían engañar a sus maridos, lo que documentalmente es muy excepcional a juzgar por los pocos casos de las que tuvieron hijos fuera del matrimonio, e insinuaba también que ellos se hacían los remolones en volver a su tierra. Así por ejemplo, en un sainete de 1790, don Ramón de la Cruz incluyó una escena en la que unas segadoras gallegas llegaban a un pueblo de Castilla buscando a sus maridos, que se habían quedado en los lugares a donde habían ido a segar y que, una vez localizados, se los llevaban de vuelta a sus casas ${ }^{15}$. La realidad era más dramática, y lo que se producía era una desarticulación familiar que dejaba a las mujeres en complicadas situaciones, en especial cuando ellos no volvían o no se sabía su paradero sin haber dejado un poder escrito que les permitiera actuar en su ausencia ${ }^{16}$.

En lo que se refiere a la situación legal de las mujeres de ausentes, es innegable que era peor que la de las viudas, no solo porque estas tenían una autonomía

13. Comprobada por Rial García, S.: Mujer y actividad económica en la Galicia Moderna. La inserción de las mujeres en la producción económica rural y urbana. Santiago de Compostela, 2003.

14. MarTín García, A.: Demografía y comportamientos demográficos en la Galicia moderna: la villa de Ferrol y su tierra, siglos XVI-XIX. León, 2005, p. 140; GONZÁLEZ DE UlLOA, P.: Descripción de los Estados de la Casa de Monterrei en Galicia en el año 1777. Santiago de Compostela, 1950.

15. Rey Castelao, O.: «Galicia y Portugal en la Edad Moderna. Intercambios socioculturales», en Hernández Borje, J. y González Lopo, D. L. (Eds.): Pasado e presente do fenómeno migratorio en Galicia. Santiago de Compostela, 2007, pp. 85-116, y «Las campesinas y el honor en la Galicia moderna», en CANDAU CHACÓn, M. ${ }^{a}$ L. (Ed.): Las mujeres y el honor en la Europa Moderna. Huelva, 2014, pp. 417-440.

16. La dimensión humana de estas gallegas se constata en los casos localizados en Andalucía: Pascua SÁnchez, M. ${ }^{a}$ J. de la: «La cara oculta del sueño indiano: mujeres abandonadas en el Cádiz de la carrera de Indias», Chronica Nova, 21, 1993-94, pp. 441-468; Mujeres solas: bistorias de amor y de abandono en el mundo bispánico. Málaga, 1998.

(C) Ediciones Universidad de Salamanca / ®@ Stud. his., H. ${ }^{a}$ mod., 38, n. 2 (2016), pp. 201-236 
OFELIA REY CASTELAO

CRISIS FAMILIARES Y MIGRACIONES EN LA GALICIA DEL SIGLO XVIII DESDE UNA PERSPECTIVA DE GÉNERO

casi total, sino porque además, podían acogerse a procedimientos legales que las protegían, como la denominada provisión «ordinaria de viudas» que en Galicia les permitía acudir directamente a los jueces de la Real Audiencia y con ello eludir a las justicias locales, más proclives al abuso. En lo referente a las casadas, las Leyes de Toro de 1505 estipulaban los actos que requerían licencia marital -renunciar a una herencia y aceptarla sin beneficio de inventario, contratar o eximir a la otra parte de las obligaciones originadas en un contrato, comparecer en juicio, etc.- lo que las dejaría en un limbo legal en caso de ausencia de los maridos, si estos no les habían dejado un poder o licencia expresa. Sin embargo, opinamos que se ha exagerado mucho sobre esas limitaciones, ya que, en realidad, la ausencia de los maridos mitigaba la subordinación femenina. En efecto, cuando ellas se convertían en responsables únicas de una explotación agraria o campesino-pesquera, o incluso de actividades artesanales, tenían que seguir pagando impuestos y rentas y contribuyendo a las cargas vecinales, ya que la ausencia de ellos no implicaba exención alguna, salvo por pobreza manifiesta. En este sentido, y quizá porque convenía al Estado, en las fuentes fiscales con frecuencia ellas eran designadas cabezas de familia, como sucede en el Catastro de La Ensenada ${ }^{17}$. También tenían que pagar las deudas que ellos hubieran dejado o contraídas por ellas, o se veían precisadas a vender bienes, acudir a la justicia o defenderse ante esta, entre muchas situaciones de riesgo para ellas y sus familias, por lo que las Leyes de Toro preveían cómo subsanar la carencia de licencia del marido cuando estaba ausente y «no se espera de próximo venir o corre peligro en la tardanza». Esto se hacía mediante una habilitación legal simple por la cual las justicias locales las autorizaban para hacer por sí mismas lo que fuese necesario y urgente para mantener a la familia o resolver una situación de crisis. Por supuesto, con la precaución legal de que a su vuelta, «el marido pueda ratificar lo que su muger oviere hecho sin su licencia no embargante que la dicha licencia no haya precedido», es decir, él recuperaba

17. Por ejemplo, en Calo, próxima a Compostela, en el Libro Personal del Catastro un $13 \%$ de los casas tenían como cabeza a mujeres con maridos ausentes, y la declaración catastral figura a nombre de ellas, mujeres jóvenes que dirigían hogares nucleares Rial García, S.: «La actuación de las mujeres de ausentes en el comercio de bienes raíces en el entorno de la tierra de Santiago, 1700-1840», en Eiras Roel, A. y Rey Castelao, O.: (Eds.): Migraciones internas, pp. 499-516. Sobre esto Rey Castelao, O. y Sobrado Correa, H.: «Fiscalidad y actividades económicas femeninas en las ciudades del Noroeste español a finales del Antiguo Régimen», en XXVI Encontro da Ass. Portuguesa de $H^{a}$ Económica e Social. Ponta Delgada, 2006. Para comprobar lo elevado de estas cifras, baste decir que en la España centro-meridional, la misma fuente catastral da menos de un dos por ciento del total eran mujeres casadas al frente de sus hogares (véase GARCía GonZÁlez, F.: «Investigar la soledad: Mujeres solas, casa y trayectorias sociales en la Castilla rural del Antiguo Régimen», Obradoiro de Historia Moderna, 24, 2015, p. 147.

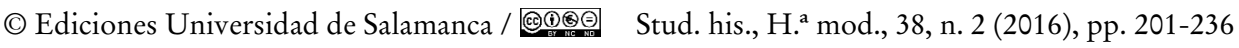


OFELIA REY CASTELAO

CRISIS FAMILIARES Y MIGRACIONES EN LA GALICIA DEL SIGLO XVIII DESDE UNA PERSPECTIVA DE GÉNERO

entonces la jefatura de la casa y la dirección sobre la economía familiar. Es fácil deducir que, más allá de concepciones paternalistas protectoras de las mujeres, ese mecanismo de sustitución estaba previsto y funcionaba en la práctica porque convenía a los poderes, a los rentistas y a los acreedores. Realmente, la autonomía legal adquirida de ese modo, lejos de ser un privilegio o un reconocimiento del papel de las mujeres como gestoras de la familia, de la casa y de los bienes, en la mayoría de los casos solo sirvió a las mujeres de ausentes para salir de situaciones de emergencia, lo que no obsta para que hubiera situaciones positivas.

En Galicia, la documentación lo demuestra con claridad. No podemos presentar una referencia cuantitativa de la frecuencia de estas situaciones, por cuanto la información aparece de forma fragmentaria en poderes notariales, demandas ante las justicias señoriales o ante a Real Audiencia para pedir licencia, o en pleitos civiles y causas criminales, incluso en comentarios explicativos en compraventas de bienes y escrituras de obligaciones o de censo. Pero podemos aportar varios casos que responden a circunstancias bastante comunes, entresacados de esas fuentes, en las que las mujeres exponen con dramatismo sus problemas personales y se lamentan de no saber del paradero de sus maridos, de ignorar si estaban vivos o muertos, o de que nunca les mandaban dinero para alimentarse y vestirse ellas y sus hijos, y, cuando pedían auxilio a la Real Audiencia, de quedar expuestas a las arbitrariedades de las justicias locales ${ }^{18}$.

En lo referente a las mujeres que solicitaron autorización de las justicias ordinarias para acudir a los tribunales o para comparecer en juicio y defender sus intereses y los de sus familias, la casuística es variada, pero siempre apunta hacia situaciones de verdadera necesidad. Así por ejemplo, en 1752 Josefa de la Torre recurrió a pedir licencia ante la justicia para poder vender una parte de los bienes gananciales, en razón de que su marido se había ido a Portugal, y en su ausencia se había visto obligada a pedir prestados dinero y una vaca con la que cultivar sus bienes; como consecuencia de su impago fue embargada por 217 reales, para lo que fue autorizada, previa declaración de tres testigos que corroboraron su información; con la licencia en la mano, Josefa pudo vender tres parcelas de tierra a su propio acreedor, que le dio por el lote 242 reales $^{19}$. El caso de María García, de Villestro, sucedido en 1772, es parecido: por su declaración ante notario en

18. Rial García, S.: «Las mujeres en el tribunal de la Real Audiencia de Galicia: una reflexión», II Coloquio Internacional AEIHM, Mujeres y ciudadanía. Santiago de Compostela, s. p. Rey Castelao, O.: «Las mujeres gallegas ante los tribunales: la defensa de lo suyo», Historia et Ius, 9, 2016.

19. Archivo Histórico Provincial de Pontevedra [en adelante AHPP], Protocolos notariales, leg. 1334 (3), fols. 65 y 67.

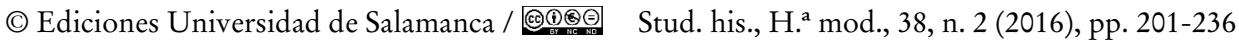


una escritura de compraventa, sabemos que los bienes que le pertenecían por su herencia y por compras hechas con su marido en régimen de gananciales, fueron embargados mediante libramiento ejecutorio para saldar las deudas que él tenía con José García, vecino de Compostela; de hecho, esas deudas eran la causa de que él se hubiera ausentado, de modo que ella se había visto en la necesidad de solicitar autorización para comparecer ante notario y enajenar los bienes de ambos, lo que hizo a favor del acreedor, que recibió doce parcelas en ochocientos reales, la misma cifra que le debía ${ }^{20}$. Como ayuda y no como préstamo, explicaba en una compraventa María Calvo, de Santa Cristina de Fecha, haber recibido un dinero; el marido se había ausentado hacía muchos años, de modo que, con licencia, en 1796 procedió a vender por 639 reales, tres parcelas a dos vecinos suyos diciendo de ellos que la socorrían en sus aflicciones ${ }^{21}$. En marzo de ese mismo año, Manuela de San Martín fue facultada legalmente para vender sus bienes hasta un total de 1.800 reales, mediante una solicitud a la justicia en la que explicaba que tenía cuatro hijos pequeños y que había contraído diferentes créditos, y que desde hacía dos años no podía pagar la renta de su casa, por lo cual se la pretendía ejecutar; en una primera operación, María se desprendió de doce parcelas que fueron valoradas en 1.530 reales y cinco meses más tarde vendió a la misma persona por 437 reales otras cinco, procedentes, igual que las primeras, de la herencia recibida de su padre ${ }^{22}$. Un poco diferente es el caso de María da Fraga, cuyo marido estaba en paradero desconocido, y que en 1797 compareció ante un notario para declarar que debía 2.200 reales al monasterio de Poio, lo que la obligaba a suscribir dos operaciones de venta a dos comerciantes de Pontevedra, por valor de 1.482 reales y 390 reales respectivamente y con ello saldar la primera deuda ${ }^{23}$. En todos estos casos y en otros que podrían citarse, se trata de mujeres que, aun pasando por situaciones de verdadera crisis, tenían bienes que vender.

En otros, la situación era realmente más grave, tuvieran bienes o no. En 1754, Juan Infante, vecino de A Graña, junto a Ferrol, demandó a Juana González, mujer de Lucas Crespo, asegurando que le había dado en préstamo 220 reales ante testigos en febrero de aquel año; en este caso es el demandante quien informa de que el marido de ella estaba ausente desde hacía muchos años en paradero desconocido, y que con ese motivo ella no le devolvía el dinero: el juez de Ferrol no dudó en

20. Archivo Histórico Universitario de Santiago de Compostela [en adelante AHUS], Protocolos notariales, leg. 6710, fol. 4.

21. AHUS, Protocolos notariales, leg. 5687, fol. 50.

22. Idem, leg. 7316 , fols. 17 y 39.

23. Idem, legs. 1426 (7), s.f. y 1427 (7), s.f.

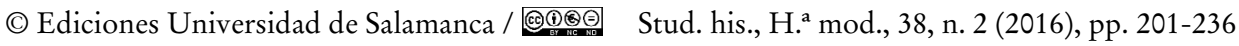


OFELIA REY CASTELAO

CRISIS FAMILIARES Y MIGRACIONES EN LA GALICIA DEL SIGLO XVIII DESDE UNA PERSPECTIVA DE GÉNERO

ordenar a Juana que devolviese el dinero y en embargarle sus bienes ${ }^{24}$. En 1781, Antonia Román, vecina de Baíñas, mujer de Pedro Álvarez, fue a parar ocho días en la cárcel de Baiona por impago de una deuda contraída con un comerciante al que debía «géneros que al fiado» llevados de su tienda «para con ellos hacer ropas con que vestir la desnudez de mis hijos», según consta en la petición de permiso que Antonia presentó ante el Corregidor de la villa para vender «tres cuartas de tierra de su marido y él está obligado a mantenerlos y no hacerlo», ya que se había ausentado, «sin saberse de su paradero» ni haber enviado dinero a su familia ${ }^{25}$.

La penuria económica tuvo que ser más grave para las mujeres de ausentes que solo contaban con los exiguos ingresos de su trabajo. En 1767, Catalina de Alfaro, vecina de San Miguel de Fofe, arriera de vino, interpuso una demanda contra un vecino que había pretendido privarla de las dos mulas que tenía para trabajar, para lo cual Catalina exhibió el poder que su marido le había dado antes de irse a Castilla a «sus menesteres, tratos y comercio», sin saber cuándo regresaría; el conflicto de las mulas derivaba de una deuda atrasada del marido que el demandado pretendió cobrarse «cogiéndole dos mulas y llevándolas a vender a la feria de la Cañiza... por aflixir a una pobre muger en ausenzia de su marido dejándola y a éste pobres y aniquilados». La Real Audiencia, en este caso, dictó sentencia a favor de ella ${ }^{26}$. La pobreza por la que en 1789 pasaban Joaquina Martínez Sarmiento, casada, regatona de pescado, y otras vecinas suyas de Pontevedra, derivaba de que sus maridos estaban ausentes y de que ellas vivían de una actividad laboral, la reventa de pescado, que se había visto prohibida por el procurador de la villa, dejándolas en una penuria extrema, por lo que se vieron obligadas a recurrir ante el Comisario de Marina para que no se les impidiese ese comercio, lo único que les permitía eludir la mendicidad ${ }^{27}$.

Un poco diferente es el caso de María Méndez, vecina de Santiago, casada con Joseph García, maestro sangrador, ausente «sin saberse si es vivo o muerto», y

24. Archivo del Reino de Galicia [en adelante ARG], Juzgado de Ferrol, 4921/29.

25. AHPP, Protocolos notariales, leg. 2766 (3), caso citado entre otros por García García, M.: «La emigración en un sector de las Rías Bajas gallegas: el ejemplo de la Jurisdicción de Bayona, 1650-1800», en Eiras Roel, A. y Rey Castelao, O.: (Eds.): Migraciones internas, op. cit., pp. 427-444.

26. ARG, Real Audiencia, leg. 10552/30.

27. «Joaquina Martínez Sarmiento, muger de Alonso Maneiro, marinero matriculado, ausente de este Reyno..., expongo a V.S. que para el mejor govierno de mi vida me balgo de tomar quando Dios lo da el pescado a los propios dueños que lo pescan para beneficiarlo al público en la plaza, y no en otro sitio como es constante y notorio..; pero hemos hallado la novedad que... se nos embargó una poca de sardina por el Procurador General de esta villa..., dejándonos desamparadas de nuestro comercio y ganancia casi a mendigar... Suplicamos a V.S. se sirba providencia a efecto de que prosigamos en nuestro trato como asta ahora...» AHPP, Fondos municipales, leg. 2 (7).

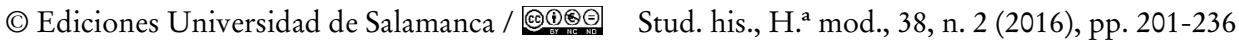


OFELIA REY CASTELAO

CRISIS FAMILIARES Y MIGRACIONES EN LA GALICIA DEL SIGLO XVIII DESDE UNA PERSPECTIVA DE GÉNERO

habilitada por la justicia para comparecer en juicio. En 9-6-1796 otorgó un poder a procuradores de número en las Audiencias Arzobispales para que la defendiesen en el pleito que había iniciado contra su marido en orden a la satisfacción de su dote y bienes capitales con la parte de los gananciales habidos durante el matrimonio, en los cuales, además, su suegra, Josefa Freire de Andrade, alegaba tener ciertos derechos. El 2 de septiembre, María dio otro poder para apelar ante la Real Audiencia, en cuya escritura explica que a su matrimonio había aportado una dote que ascendía a 5.850 reales y que para asegurar ese valor, el marido le había hipotecado la mitad de la casa en que vivían en la calle del Franco y que adquirieron ya casados. La casa fue tasada en 9.533 reales, de manera que María solicitó el reintegro de su dote en la otra mitad. La suegra, a su vez, reclamó la citada mitad, y el juez ordinario había emitido una sentencia a favor de esta, lo que obligó a María a apelar ante la Audiencia. El litigio se solucionó mediante un convenio por el que María podría seguir ocupando toda la casa, costeando las reparaciones, pagando las rentas y un alquiler de 165 reales anuales a su suegra mientras la habitase. María Méndez aparece poco después en otra escritura de poder, en compañía de una hermana, litigando contra un vecino de Suevos que, según ellas, las había engañado en el precio con el que les pagó la compra de sus legítimas de bienes ${ }^{28}$.

Con más frecuencia que para emprender o seguir acciones judiciales desesperadas, las mujeres de ausentes fueron habilitadas por la justicia para vender bienes o para pedir préstamos, mediando testigos que certificaban la situación de necesidad que las obligaba a hacerlo, si es que los maridos no las habían habilitado antes, y muchas veces a petición de la otra parte contratante. Debe recordarse que ellas no necesitaban permiso marital para hacer testamento, notarial o no, de modo que en muchas escrituras aparecen esposas de ausentes haciendo mejoras en beneficio de quienes iban a cuidarlas en su ancianidad, más de una vez añadiendo cláusulas para el caso de que los maridos retornasen una vez muertas ellas y pretendieran hacer cambios en sus disposiciones; es decir, se preveían posibles situaciones de crisis de las más comunes, como las hereditarias o el siempre elevado gasto de entierro y funerales ${ }^{29}$.

28. AHUS, Protocolos notariales, legs. 6900, fol. 35, 8596, fol. 143, 6294, fol. 49 y 6900, fol. 54 .

29. En 1796, M. Antonia Naveiro tenía ausentes su marido y un hijo, por lo que ante notario hizo una mejora a favor de una hija, a condición de que si regresase el marido, podría usufructuar los bienes raíces mientras la hija no se casara. En ese año, Antonia Pérez, casada con Juan de Ameiro, ausente desde hacía años sin saberse dónde, mejoró a su hija Dominga, casada y en su compañía, aunque tenía otras dos hijas, a cambio de lo cual aquella se comprometía vivir con ella y a costear su entierro en AHPP, Protocolos notariales, leg. 1162 (4), fol. 93 y AHUS, Protocolos notariales, leg. 5687, fol. 29.

(C) Ediciones Universidad de Salamanca / ®@ Stud. his., H. ${ }^{a}$ mod., 38, n. 2 (2016), pp. 201-236 
La frecuencia de las operaciones de crédito hechas por mujeres ante notario está siendo objeto de estudio ${ }^{30}$, aunque se intuye que gran parte de las que asumieron las mujeres de ausentes se hicieron de forma privada, como se ve en varios de los ejemplos anteriores y sobre todo en las compraventas de bienes. Como demostró S. Rial García en un estudio monográfico sobre la Tierra de Santiago, la mayoría de las ventas hechas por esas mujeres eran el fatal corolario de una cadena de pequeños préstamos en el ámbito familiar o vecinal más próximo; para probar que en realidad eran compraventas «falsas», hay un dato revelador: que muchos compradores, una vez pactadas las operaciones de venta y sus condiciones, exigieran el permiso judicial para hacerlas efectivas. Pero es más revelador todavía el hecho de que, a lo largo del xviII, fue cada vez más frecuente que el precio de la venta no se pagase ante el escribano, sino que se había percibido con anterioridad, de modo que si a comienzos de ese siglo esa fórmula era poco frecuente, a finales, más de la mitad de las ventas respondían a esa práctica ${ }^{31}$.

Las mujeres de ausentes que venden bienes, revelan una apremiante necesidad de dinero y sus estrategias de pequeños préstamos avalan la idea de los ilustrados de un endeudamiento mayor por parte de las mujeres en ausencia de sus maridos. Ahora bien, la pregunta que surge de esta constatación es si las mujeres de ausentes se vieron perjudicadas de un modo especial o si forman parte de del contexto general. La propia Serrana Rial subraya varios datos comparativos que no conviene desdeñar. En primer lugar, que durante el xviII se incrementó constantemente y con fuerza el porcentaje de mujeres compradoras de bienes, al compás del aumento de la movilidad masculina, ya que en las escrituras ellas hacen constar que compraban con dinero enviado por los maridos ausentes; en estos casos, las que compraban lo hacían normalmente a hombres y pagaban por las tierras adquiridas un precio sensiblemente superior al precio medio de la zona. En segundo lugar, hay varios síntomas que apuntan en varios sentidos: el de la solidaridad familiar y vecinal o la esperanza por parte de los acreedores de recuperar el préstamo con las aportaciones de los maridos en caso de que retornaran. Esto explicaría algunos datos "positivos» que las diferenciaban de las viudas y de las solteras, en especial el mayor precio obtenido por los bienes vendidos. En la muestra realizada por S. Rial, en un total de 1.317 compraventas con intervención de mujeres, aparecen 1.406 compradoras y vendedoras, campesinas en su inmensa mayoría, de las que eran vendedoras tres de cada cuatro; la mayor parte eran viudas

30. Cebreiro Ares, F.: «Women and Credit in the Region of Santiago de Compostela at the end of Old Regime». Women and Credit in Preindustrial Europe, International Symposium, Universidad de Umea, 30-31/5/2016.

31. Rial García, S.: «La actuación de las mujeres de ausentes», pp. 499-516.

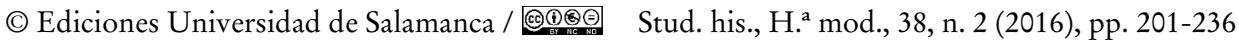


OFELIA REY CASTELAO

y no era desdeñable el número de solteras $-15 \%$ de las operaciones, llegando al $25 \%$ a fin de siglo-. La intervención de las casadas es notable y a lo largo del xviII fue creciendo el porcentaje de las mujeres de ausentes en el comercio de bienes raíces, al hilo del incremento de la emigración de casados; sobre todo al fines del siglo, ellas se vieron obligadas a desprenderse de bienes, lo que encaja con la fase de empobrecimiento relativo que afectó a la Galicia occidental desde la crisis de 1768/69, acompañada del progresivo deterioro del nivel de vida campesino. En estos casos, las escrituras suelen ser bastante explícitas, y ofrecen datos narrativos de interés. Así se constata que en torno a tres de cada cuatro casadas declararon actuar por sí mismas porque sus cónyuges se hallan ausentes y acudían al notario con su autorización. Dado que el paradero desconocido de los maridos era tanto una razón para actuar como el pretexto para obtener la licencia legal, raras veces se mencionan los destinos, pero cuando se explicitan, Cádiz aparece como el más frecuente, y en menor medida Castilla o Portugal, lo que encaja con el modelo migratorio de esta zona de Galicia ${ }^{32}$. Sucede lo mismo con la duración de las ausencias, cuyas infrecuentes menciones van de los tres años a más de veinte, lo que revela la prolongación de la ausencia temporal y el fracaso de la estrategia migratoria en una gran parte de los casos. Precisamente por las seguridades que los compradores/acreedores exigían para precaverse de problemas en caso de regreso de los ausentes, las escrituras explicitan en más del sesenta por ciento de los casos la naturaleza de los bienes vendidos, lo que permite ver que una de cada tres mujeres vendió bienes de su propia herencia, y el resto, gananciales o bienes de los maridos. Y la inmensa mayoría de ellas decían hacerlo por deudas anteriores a la marcha de los cónyuges -de hecho, con frecuencia aducen que su ausencia había sido causada por la imposibilidad de pagarlas- o bien por otras contraídas en ausencia de ellos, y que esas deudas les impedían alimentar a sus hijos y las exponían al peligro de un embargo de sus bienes. Cuando las mujeres casadas declaran el monto de esas deudas, el $65 \%$ se sitúan entre 300 y 1.000 reales y el resto lo hace entre 1.100 y 3.600 reales.

Ahora bien, como antes decíamos, hay datos «positivos» dentro del dramatismo que reflejan estas situaciones. En primer lugar, las casadas con cónyuge ausente obtenían por sus tierras mejores precios, de un índice 100 a principios del XVIII a 452 a fin de siglo, casi un $36 \%$ más que entre el total de las vendedoras, y en general por encima del precio medio, que se elevó de forma constante e intensa, pasando de un índice 100 en 1700 a 369 hacia 1800 como reflejo de una coyuntura que pasó de la fase de plenitud agraria, con algunas crisis graves como la de

32. Rey Castelao, O.: «La emigración a América en la cuenca media del Ulla: un ejemplo de análisis comarcal», Revista Galega do Quinto Centenario, 4, 1990, pp. 177 a 224.

(C) Ediciones Universidad de Salamanca / ®@ Stud. his., H. ${ }^{a}$ mod., 38, n. 2 (2016), pp. 201-236 
1710, a un final de estancamiento, mediando entre esos extremos una creciente demanda de tierras motivada por la presión demográfica y porque los campesinos acomodados o los que podían hacerlo, buscaron tierras en el mercado como forma de inversión, y fueron los principales beneficiarios de las crisis privadas; sin embargo, la oferta de tierras era cada vez menor porque los campesinos, incluso los más endeudados, cada vez tenían menos bienes para poner en circulación ${ }^{33}$. Esto explicaría el hecho de que la superficie de las tierras vendidas fuese cada vez más reducida, de unos 958 metros cuadrados a comienzos del xviII, a 320 a fines de siglo, un descenso del sesenta por ciento, muy superior a la media, y quizá también podría explicar la relativa ventaja que obtuvieron las mujeres de ausentes. Por el contrario, el hecho de que cerca del sesenta por ciento de los compradores sean vecinos de las vendedoras sugiere que quizá las mujeres de ausentes suscitasen adhesiones en comunidades donde la amenaza de emigrar afectaba a la mayoría, obteniendo un mayor precio por sus bienes.

En definitiva, en Galicia, en especial en su mitad occidental, proliferaron durante el XviII las mujeres casadas y jóvenes que asumieron la responsabilidad de sus familias cuando sus maridos emigraron en su plenitud laboral y reproductiva, y cuando más bocas había que alimentar y menos las manos capaces de producir. Las mujeres dirigían la casa y la explotación, pero también tuvieron que seguir pagando impuestos y rentas, hacer frente a crisis de subsistencias, luchar o defenderse ante la justicia, endeudarse o vender bienes para cubrir sus deficiencias si no recibían dinero de sus maridos o ellos no volvían a su tierra, lo que no era infrecuente, habida cuenta del importante porcentaje de los que fallecían en el transcurso de sus ausencias o que buscaban otros destinos. A cambio, ellas pudieron beneficiarse de un margen notable de autonomía legal y de independencia práctica, ventajas envenenadas en la mayoría de los casos, como acabamos de ver.

\section{Ellas también TENíAN QUE IRSE DE CASA}

Si las mujeres casadas, salvo una minoría, fueron el elemento estable de las familias en ausencia de los hombres y los sustituyeron plenamente cuando ellos emigraron y no retornaron, muchas solteras se vieron en la precisión de emigrar

33. Tilves Diz, J.: «Las compraventas de tierras en la comarca compostelana en los siglos XVII-XVIII», en EIras Roel, A. (Ed.): La Documentación Notarial y la Historia. Santiago de Compostela, 1984, p. 420; SAavedra Fernández, P.: «Un aspecto de las crisis de subsistencia en la Galicia del Antiguo Régimen: las ventas de tierra», en EIRAs Roel, A. (Ed.): La historia social de Galicia. Santiago de Compostela, 1981, pp. 161-180; Villán de la Fuente, O.: «Crisis agraria y transferencias de propiedad: el "gran invierno" de 1710 reflejado en las ventas de tierra», ib., pp. 193-194.

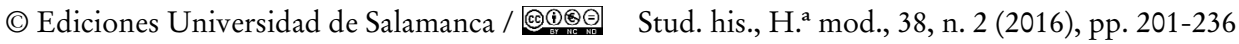


OFELIA REY CASTELAO

CRISIS FAMILIARES Y MIGRACIONES EN LA GALICIA DEL SIGLO XVIII

DESDE UNA PERSPECTIVA DE GÉNERO

para resolver sus propias crisis personales, las que se producían cuando tenían que resolver sus vidas porque sus familias no podían asegurarles el futuro. Las mujeres solteras en edad nupcial y laboral eran mayoría en Galicia -131.905 de 16 a 40 años frente a 108.681 hombres en 1787 , el $54,8 \%$ - y una parte de ellas, imposible de calcular, partió hacia las ciudades y villas de Galicia o de fuera de esta, en Castilla o en Andalucía, y un sector protagonizaba cada año una migración estacional para ir a segar a los campos de la Meseta septentrional. Es esta dimensión a la que dedicamos la segunda parte de nuestro trabajo.

Estudios de los años ochenta y noventa del siglo xx, clasificaron la movilidad femenina en función de su causalidad y no de su intensidad, un planteamiento menos rígido que los anteriores, que da prioridad a la migración del campo a la ciudad y reivindica la importancia de las historias de vida y los estudios de casos para captar las causas personales o sociales de la movilidad, muchas veces más importantes que las razones económicas ${ }^{34}$. Estando de acuerdo con esta orientación, en varias ocasiones hemos subrayado que se descuidan los desplazamientos entre núcleos urbanos de rango diferente, la movilidad en el propio medio rural y las tipologías temporales y espaciales clásicas ${ }^{35}$; además, mantienen la percepción estereotipada del papel de las mujeres en la migración, que las ve como acompañantes de los hombres o aisladas en las casas, lo que no encaja con muchos casos europeos en los que las mujeres tuvieron que irse de casa para obtener un ingreso del que vivir o para mantener a los suyos, y lo hicieron a lugares distantes, rompiendo con frecuencia las famosas leyes de Ravenstein que las limitaban a las distancias $\operatorname{cortas}^{36}$.

Por otro lado, a fuerza de buscar casos individuales, no se consigue una visión de conjunto; más bien, al contrario, se corre el riesgo de convertir lo excepcional en normal. Citemos varios ejemplos de mujeres gallegas que protagonizaron algunas de esas historias. Ese fue el caso de María Antonia Pereira do Campo, de Baiona, mujer casada, madre de dos hijos, quien en 1723 emprendió el camino a pie hasta

34. JiméneZ Julia, E.: «Una revisión crítica de las teorías migratorias desde la perspectiva de género", Arenal, 2, 1999, pp. 239-263.

35. Rey Castelao, O.: «Las migraciones femeninas de Antiguo Régimen en su contexto europeo», en Hernández Borje, J. y GonzÁlez Lopo, D. L. (Eds.): Mujer y emigración, una perspectiva plural. Santiago de Compostela, 2008, pp. 39-67; «L'effet des régimes démographiques et des systèmes familiaux sur la participation aux flux migratoires», en ORIs, M. (Ed.): Une démographie au féminin. Risques et opportunités dans le parcours de vie. Berna, 2009, pp. 25-62.

36. Dallera, C. y Ducret, V. (Eds.): Migration feminine. Au delá des stereotypes, s. 1. 2004; Arango, J.: «Las “Leyes de las Migraciones” de E. G. Ravenstein, cien años después», Reis, 32, 1985, pp. 7-26.

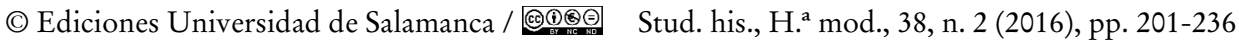


OFELIA REY CASTELAO

CRISIS FAMILIARES Y MIGRACIONES EN LA GALICIA DEL SIGLO XVIII DESDE UNA PERSPECTIVA DE GÉNERO

Sevilla para conseguir la separación de su marido, emigrado en aquella ciudad y fracasado en su intento de conseguir recursos para mantener a su familia; el viaje lo hizo acompañada por dos vecinas, atravesando Portugal, con escalas donde había parientes o conocidos suyos, para acabar en Madrid, ciudad en la que encontró una solución para su vida y la de su familia ${ }^{37}$. ¿Qué hacía y dónde estaba María Antonia Fernández, de San Martín de Lamas, de la comarca ourensana de Celanova, de 25 años, apresada en la bahía de Safi en 1757 y que fue rescatada dos años después en Marruecos?; es de sospechar que estaría en alguna zona andaluza ${ }^{38}$. Sabemos más del periplo de Ángela Castro, de Santa María de Mosteiro, que se quedó embarazada de una relación con el italiano José Losa, maestro peltrero, hojalatero y vidriero; se conocieron en Lugo y todo indica que ella se fue con él, ya que en 1807 figura como su criada en Valladolid, cuando, de nuevo embarazada, lo acusó ante la Chancillería por haberla echado de la casa en la que vivían amancebados. Los alcaldes del crimen no dudaron en ordenarle en aquel año que se volviera al hogar de sus padres, lo que repitieron de modo perentorio en un auto de 20 de octubre de 1808 por el que se la confinaba en Mosteiro; al mismo tiempo se sobreseía la causa de oficio por amancebamiento y escándalo público iniciada por la justicia de Valladolid y no se atendía la demanda de Ángela acusando a José Losa de estupro y malos tratos; este sobreseimiento hizo que la causa muriese, por lo que no es posible saber si ella y sus dos hijos retornaron a aquella aldea lucense ${ }^{39}$.

Son historias singulares y poco representativas en las que se intuyen causas comunes a otras mujeres, pero desde nuestro punto de vista, es importante tratar de llegar a un comportamiento conjunto. Adelantamos ya que las gallegas estaban entre las mujeres más proclives a la emigración a distancias medias o largas, y que los lugares a donde se desplazaban en el XviII guardan semejanzas con los frecuentados por los hombres; pero también podemos decir que en este siglo, el aumento constante de la emigración masculina retuvo a muchas en sus casas y que a esto quizá contribuyó la proto-industria textil, de modo que el movimiento pudo ser más intenso en el siglo xviI. Para comprobar ambos aspectos, reuniremos todos los datos existentes de los lugares de origen, pocos en realidad, y de llegada, más abundantes pero centrados en ciudades de Galicia y de fuera de esta.

En cuanto a lo primero, se ha podido constatar que entre los 377 ausentes de 61 localidades de la antigua provincia de Santiago recogidos en el padrón de 1708 -un

37. Este caso, en Rey Castelao, O.: «Las campesinas y el honor», ya citado.

38. Maziane, L.: «Los cautivos europeos en Marruecos, siglos XVII-XVIII», en MartíneZ Torres, J. A. (Dir.): Circulación de personas e intercambios comerciales en el Mediterráneo y en el Atlántico, siglos XVI, XVII, XVIII. Madrid, 2008, p. 76.

39. Archivo de la Real Chancillería de Valladolid, Salas de lo Criminal, caja 15, 7.

(C) Ediciones Universidad de Salamanca / ®@ Stud. his., H. ${ }^{a}$ mod., 38, n. 2 (2016), pp. 201-236 
momento de guerra que retrajo los desplazamientos masculinos-, había un 4,2\% de mujeres, cuyo estado y destino no se mencionan. En la provincia de Lugo en la misma fuente y fecha se ha podido constatar que en su parte central -Castro de Rey, Luaces, Pol, etc.- ellas eran el 7,1\% de los ausentes; en las escrituras notariales de Pol se detecta un 3,5\% de mujeres entre las noticias de ausentes en la primera mitad de siglo y un 10,1\% en la segunda, y en Narla-Friol, $29,4 \%$ y $9 \%$ respectivamente, tratándose en un $72-75 \%$ de mujeres solteras y el resto casadas, proporción esta última mayor que la de hombres casados, en torno al 3 o $4 \%{ }^{40}$. En las partidas de defunción de la jurisdicción de Baiona, el 2,42\% de muertos fuera eran mujeres, pero estaban cerca, desde Pontevedra por el Norte a Valença do Miño por el Sur, y todas eran criadas ${ }^{41}$, y en las de la ciudad de Lugo, como veremos, llegaban a ser una quinta parte de los ausentes.

Por lo que respecta a lo segundo, atenderemos primero a los movimientos clásicos hacia las ciudades, que como en todas partes, constituían el destino migratorio femenino más frecuente, sobre todo para las mujeres jóvenes que iban a buscar trabajo, cambiar de estado u ocultar un embarazo, desde un círculo cuyo radio dependía del tamaño y funciones de las ciudades y de la coyuntura económica, ya que en períodos de expansión aumentaba la demanda urbana de hombres. Galicia no se escapaba a esa dinámica, a pesar de que en el siglo xviI sus ciudades y villas seguían siendo pequeñas y tradicionales por lo que su capacidad de atracción era limitada.

Por una parte, era importante la oferta asistencial, que explica la presencia de muchas mujeres pobres en los recuentos de población de $1708 / 9$ o de 1753 y en los censos de 1768/69 y 1787. A veces aparecen muertas a la puerta de iglesias o asilos, como registró en 23-VII-1695 el párroco de San Miguel dos Agros de Santiago, dando cuenta de haberse hallado a «una pobre labradora, no se sabe como se llamaba ni de adonde era»; lo mismo hizo el de Santa María del Camino en 1710, que menciona haber enterrado «en la Angustia una muchacha al parecer de catorze años, dixeron ser hixa de Juan Bravo, vecino de Angrois y María Caballero, dixeron ser de la Coruña ${ }^{42}$. Por otra, se constata la frecuente presencia de jóvenes rurales o de otros núcleos urbanos, que habían llegado para dar a luz a hijos ilegítimos; lo

40. Sobrado Correa, H.: Las tierras de Lugo en la Edad Moderna: economía campesina, familia y berencia, 1550-1860. La Coruña, 2001, p. 375.

41. García García, M.: «La emigración en un sector de las Rías Bajas gallegas: el ejemplo de la Jurisdicción de Bayona, 1650-1800», en Eiras Roel, A. y Rey Castelao, O. (Eds.): Migraciones internas, op. cit., pp. 427-444.

42. Archivo Histórico Diocesano de Santiago, Archivos parroquiales. Sobre esto, Barreiro Mallón, B. y Rey Castelao, O.: Pobres, enfermos y peregrinos. La red asistencial gallega en el Atiguo Régimen. Vigo, 1999.

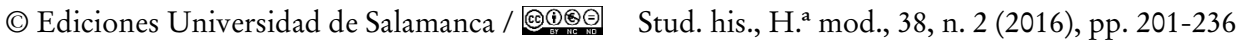


OFELIA REY CASTELAO

CRISIS FAMILIARES Y MIGRACIONES EN LA GALICIA DEL SIGLO XVIII DESDE UNA PERSPECTIVA DE GÉNERO

más probable es que retornaran a sus lugares de origen, aunque no siempre ${ }^{43}$. Este tipo de casos revela el dramatismo de muchas trayectorias vitales.

Pero sobre todo las mujeres buscaban las ocupaciones laborales urbanas, cuya tasa era más elevada en las ciudades gallegas que en la mayoría de las ciudades de la Corona de Castilla ${ }^{44}$, aunque vinculada al sector de servicios en general y al doméstico en particular, baste decir que en Santiago se recontaron más de novecientas criadas en 1753 y en Lugo 478. Se trataba en muchos casos de empleos temporales que devenían definitivos, cuando no encontraban marido u otra salida, y las criadas acababan sus días en las casas de sus amos; Serrana Rial en Compostela y Hortensio Sobrado en la capital lucense, localizaron muchos ejemplos como el de Manuela de Romay, de San Ciprián de Recesende, muerta en 1763 en la casa de doña Magdalena de Prado y de don Juan de Quiroga, a quienes había servido, por cuanto «no se le conocían parientes» y era «soltera y pobre de solemnidad»; o el de Francisca López, natural de San Esteban de la Mota, de setenta años, muerta en 1794, que "pasó la mayor parte de su vida (en Lugo) con motivo de servir» ${ }^{45}$. Es una situación habitual de fracaso que no necesita más explicaciones, como lo era el de aquellas que hubieran quedado en paro y vivían solas, algo que ponía en guardia a las autoridades urbanas, que les ordenaban buscar nuevos amos o volver a sus casas, o les prohibían o dificultaban ganarse la vida con ciertos trabajos para convencerlas de la conveniencia de un retorno, sin comprender que el regreso era peor que quedarse.

¿Pero cuántas mujeres dejaron sus casas para ir a las ciudades y villas gallegas? ¿Eran solo rurales o hubo movilidad entre núcleos urbanos y semi-urbanos? Tenemos buena información de cuatro casos significativos: Santiago, Lugo, Tui y Ferrol. Los tres primeros casos sirven para dar una idea de cuál era el comportamiento de los núcleos gallegos de corte tradicional, que, aun siendo pequeños $-17.000,3.500 / 4.100$ y 4000 habitantes en $1753 / 1787$ respectivamente- eran esenciales como lugares de referencia de las migraciones femeninas ${ }^{46}$, al igual que en Francia, de ahí la importancia que concede la reciente bibliografía francesa a este

43. Rey Castelao, O. y Barreiro Mallón, B.: «Apadrinar a un pobre en la diócesis de Santiago de Compostela, siglos XviI-XIX», en Pérez Álvarez, M. J. y LobO, M. M (Coords.): Las respuestas sociales a la pobreza en la Peninsula Ibérica durante la Edad Moderna. León, 2014, pp. 209-239.

44. Rial García, S.: Las mujeres en la economia urbana del Antiguo Régimen. Santiago durante el siglo XVIII. Sada, 1995.

45. Sobrado Correa, H.: La Ciudad de Lugo en el Antiguo Régimen: siglos XVI-XIX. Lugo, 2001, p. 40. Rial García, S., op. cit.

46. Eiras Roel, A.: «A propos de la démographie urbaine d'Ancien Régime: l'exemple des petites villes de la Galice traditionnelle», en Historiens et Populations. Lovaina, 1991, p. 399.

(C) Ediciones Universidad de Salamanca / ®@ Stud. his., H. ${ }^{a}$ mod., 38, n. 2 (2016), pp. 201-236 
OFELIA REY CASTELAO

CRISIS FAMILIARES Y MIGRACIONES EN LA GALICIA DEL SIGLO XVIII DESDE UNA PERSPECTIVA DE GÉNERO

tipo de núcleos ${ }^{47}$. Mientras que Ferrol se corresponde con un modelo diferente y propio del xVIII, el de una ciudad creada prácticamente exnovo con fines militares.

En el setecientos casi la mitad de las mujeres (48,5\%) que se casaron en Santiago de Compostela procedía de fuera de la ciudad, pero la cifra se elevaba al 74,2\% y $82,4 \%$ entre las que se casaban en sectores poco cualificados o sin profesión determinada, quizá porque eran los sectores más móviles y más abiertos a los inmigrantes, y era menor entre el artesanado (40\%), un sector muy endogámico. Sin embargo, la proporción de forasteras descendió del $65 \%$ anterior a 1730 , al $46 / 47 \%$ entre $1730-1770$, y $35 / 38 \%$ después, una disminución mayor que entre los hombres y que concuerda con la evolución de la población, en aumento hasta mediados de siglo y estancada después, si bien en números absolutos el máximo se situó en 1761/70. El control a través de actas de bautizo da un $44,6 \%$ de forasteras y corrobora su mayoría entre las mujeres de peones $(82,4 \%$ ) y de indeterminados (66\%), y la tendencia a la baja a lo largo del siglo $-61 / 65 \%$ hasta $1730,47 / 42 \%$ en 1730/1770 y 28/31\% después-, aunque aumentando en números absolutos con máximo en 1761/90. Casi todas esas mujeres procedían de la propia Galicia, y más en concreto del área situada entre los ríos Tambre y Ulla, en cuyo centro se situaba Compostela, en un radio no superior a los 40/50 kilómetros ${ }^{48}$.

En las actas de matrimonio de Lugo, el 29,1\% en la primera mitad del xviII y el $43,5 \%$ en la segunda eran mujeres de fuera de la ciudad $-53,5 \%, 40,8 \%$ entre los hombres, aunque ellas eran menos en cifras absolutas-. Ellas procedían de la zona rural próxima a la ciudad en un $71 \%$, o todo lo más de la provincia, como correspondía a una pequeña y anquilosada capital provincial. Un dato muy interesante de los publicados por Hortensio Sobrado confirma la importancia de la emigración desde la ciudad: en la segunda mitad del xviII, en las actas de defunción, el $31,7 \%$ de los muertos emigrados, eran mujeres; eran todas casadas $(46,1 \%)$ o solteras (53,8\%); entre los hombres, la proporción de solteros era mucho mayor, $82,1 \%$ y los casados solo $17,8^{49}$. En cuanto a Tuy, en las partidas de nacimiento de $1781 / 1800$ hay 592 madres forasteras, el $26 \%$, y eran gallegas un $95,1 \%$, procedentes de la provincia de Tuy y de modo más claro, de la propia comarca tudense ${ }^{50}$. En

47. Bodineau, P. y Lamarre, Ch. (Eds.): Capitales ou villes d'appui? Les petites villes et leurs campagnes du Môyen Âge au XXIe siècle. Dijon, 2014.

48. Martínez Rodríguez, E.: La población de Santiago de Compostela, 1630-1860. Estructuras, coyunturas y comportamientos demográficos. Santiago de Compostela, 2015, p. 135.

49. Sobrado Correa, H.: La ciudad de Lugo, p. 37.

50. Martínez Rodríguez, E., Burgo López, M. C., y González Lopo, D. L.: «Inmigración urbana en la Galicia del Antiguo Régimen, Santiago, Tuy y Ferrol a finales del siglo Xvirı». Migraciones internas, op. cit., pp. 479-498.

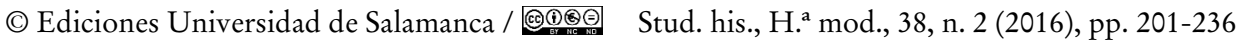


OFELIA REY CASTELAO

estos casos no podemos saber si eran pobres, pero los caracteres de ambas ciudades permiten pensar que lo serían como en Santiago.

En cuanto a Ferrol, capital del Departamento Marítimo del Norte y arsenal de la Corona, pasó de 1.251 habitantes en 1752 a 24.993 en 1787, de los que la inmensa mayoría eran hombres -en esa fecha había 5.840 solteros y solo 1.323 solteras- llegados para cubrir la demanda de mano de obra, y al rebufo de esta circunstancia llegaron muchas mujeres para trabajar como criadas, como componentes de familias inmigradas o para buscar oficios en el sector servicios ${ }^{51}$. En 1755-59 el 79\% de las novias eran de fuera -y el 93\% de los novios-, aunque su proporción decreció, como la de ellos, a medida que la ciudad se fue asentando; en el $67 \%$ en 1780 (ellos $89,6 \%$ ) y en $1790 / 99$, las forasteras habían descendido al $42.7 \%$, siendo ellos el 78,6\%. Si se recuentan las madres que figuran en las actas de bautismo, las forasteras pasan del $86,5 \%$ en $1755-59$ de las que el 53,3\% eran gallegas (ellos solo el 30,3\%), en 1780-82 el 65,2\% (ellos 82,5) de las que $86 \%$ eran gallegas (ellos 71,2\%), y en $1790-99$, el $60,7 \%$ de las madres eran foráneas (ellos 78,9\%), y de estas, $87,1 \%$ eran gallegas (71,6\% ellos). Entre el 86 y el $88 \%$ de las novias eran gallegas y procedían sobre todo del contorno rural y de las villas vecinas del arsenal, es decir, de áreas más próximas que los hombres. Pero lo más significativo es que muchas procedían de otras ciudades y villas de Galicia, en proporción mayor que los hombres: de Santiago, A Coruña, Lugo o Betanzos -menos, de Pontevedra, Mondoñedo o Tui-, de modo que la aportación urbana llegó a ser del 35,6\% de las madres en 1755/59, en la fase de inicio de la oleada migratoria a Ferrol, estabilizándose después en torno al 12/13\% del total. Llegaron también de un conjunto de villas que aportaban cada una de ellas un número reducido pero cuya suma resulta significativa: a mediados del XVIII, cuando este hecho es más visible, 17 villas de las cuales solo dos eran interiores y el resto de la costa, aportaron novias (16,4\%) y madres (17,6\%); en los años ochenta, cuando Ferrol llegó a su máximo poblacional, provenían de 35 villas diferentes -diez de interior y el resto costeras-, reduciéndose algo a fines del XVIII, de modo que en torno al $11 / 13 \%$ de las novias y el $12 \%$ de las madres eran de ese origen. Dicho de otro modo, las mujeres de procedencia urbana o semiurbana en ningún momento de la segunda mitad de siglo descendieron del 25\%, cuando la población rural de Galicia superaba el $90 \%$.

El comportamiento migratorio ferrolano es muy similar al de los puertosarsenal del Oeste francés -Brest, por ejemplo-, y encaja con un modelo propio de este tipo de ciudades en el nivel migratorio femenino y en las dedicaciones

51. Martín García, A.: Demografía y comportamientos, pp. 145-184.

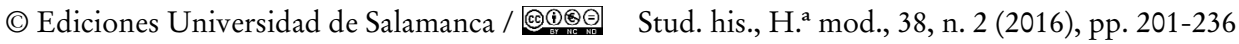


económicas de las mujeres ${ }^{52}$. En Ferrol, las mujeres no solo eran domésticas, sino que muchas se dedicaron al pequeño comercio, al menudeo de bebidas alcohólicas, al alquiler de habitaciones y locales, etc., aprovechando las oportunidades de negocio que la población militar abría en ese tipo de facetas, como sucedió en ciudades similares de España o de Francia ${ }^{53}$. El nivel de fracasos no puede medirse, pero hay un dato muy expresivo que es el enorme número de causas judiciales a las que dieron lugar las mujeres asentadas en Ferrol, motivadas por operaciones fallidas de todo tipo, y en las que la pobreza, cuando no la miseria, es claramente perceptible. Otro indicio es el denso e irresoluble problema de la marginación y de la prostitución, acompañadas del creciente número de ilegítimos y de niños abandonados, demostración de lo que era este tipo de ciudades de aluvión, repletas de hombres jóvenes en edad laboral que hacían estancias temporales y volvían a marcharse cumplidas sus obligaciones o sus objetivos ${ }^{54}$.

Pero lo más significativo de Galicia era en el XviII la emigración femenina fuera de Galicia. Antonio Meijide Pardo, el primer estudioso de la emigración gallega, calculó en su momento que las mujeres podían ser en torno a la tercera parte de los temporeros que salían de Galicia cada año en ese siglo, pero no aportaba cifras, sino impresiones obtenidas de documentación oficial en la que se condenaba la presencia femenina en ese trasiego ${ }^{55}$. En efecto, en 9-7-1736, la Real Audiencia de Galicia ordenó que no salieran a Castilla a la siega las mujeres casadas si no iban con sus maridos, y las solteras, que, según la orden, iban allí con sus padres, tíos o hermanos, y en una visita pastoral de 1742, H. Sobrado constató que se imponía a los curas de la jurisdicción de Castroverde, que, atendiendo ese mandato, hiciesen relación de las casadas y solteras que salían de sus parroquias. En 1748 la Audiencia mandó castigar con cárcel y multas a las solteras que incumplían sus órdenes, pretextando que causaban «desórdenes y ofensas a Dios» y que para ir a Castilla se valían de falsos parentescos y de la connivencia de las justicias locales. En 1751, el obispo de Sigüenza se dirigió al Intendente de Galicia para denunciar «el gran

52. Levy, A.: Brest et les brestois, 1720-1789. Brest, 1986, pp. 144-173. Jarnoux, Ph., Legallo, Y. y Roudot, F.: «Le port et sa ville au Xvine siècle», en Legallo, Y. (ed.): Histoire de Brest. Brest, 1976, p. 75.

53. Perreon, St.: «Des soldats et des profits. L'impact de la consommation militaire dans les villes bretonnes au XVIIIe siècle», en BRAgARD, Ph. y otros (Eds.): L'armée et la ville dans l'Europe du Nord et du Nord-Ouest. Lovaina, 2006, pp. 321-337.

54. El caso ferrolano en Rey Castelao, O.: «Las mujeres gallegas ante los tribunales», ya citado. Sobre el otro aspecto, MARTín Garcia, A.: «Prostitutas, pobres y expósitos. Marginados y excluidos en el Ferrol del Antiguo Régimen», Semata, 16, 2005, pp. 333-356.

55. MejJide Pardo, A.: «La emigración gallega intra-peninsular en el siglo XVIII», en Estudios de Historia Social de España, IV, 1960, pp. 463-606.

(C) Ediciones Universidad de Salamanca / ®@ Stud. his., H. ${ }^{a}$ mod., 38, n. 2 (2016), pp. 201-236 
OFELIA REY CASTELAO

CRISIS FAMILIARES Y MIGRACIONES EN LA GALICIA DEL SIGLO XVIII DESDE UNA PERSPECTIVA DE GÉNERO

número de mujeres de todas clases que con pretexto de la siega, se incorporan todos los años con las cuadrillas de hombres que vienen a Castilla, resultan malísimas consecuencias y ofensas a Dios por estar y recogerse juntos por la noche, hasta que llega el caso de retirarse a su tierra». Y en 1754 el ayuntamiento de Lugo se hacía eco de que era costumbre antigua que pasasen «las mugeres a las siegas de Castilla con las quadrillas de hombres», saliendo en mayo hacia sus destinos. En ese año, una providencia dada en Valladolid, recogía que ellas se disfrazaban e iban mezcladas con los hombres, dando aviso a las autoridades de León, Astorga, Palencia, Zamora, Ávila, Segovia y otros lugares para que impidiesen el paso aunque fueran con sus familiares y solo para segar, por lo que se ordenaba a los mayorales y cuadrilleros no llevasen mujeres so pena de veinte ducados por cada una y diez años de presidio en África, y que maridos, padres, hermanos o parientes hicieran lo mismo con respecto a las mujeres de su familia o a las criadas, encargando a los mayordomos y justicias la vigilancia, a riesgo de fuertes multas. Todavía en 1766, el conde de Aranda recordó la orden de impedir que fueran mujeres en las cuadrillas. Pero como muy bien señalaba fray Martín Sarmiento (1746), las mujeres repetían esos viajes durante varios años sin atender a las prohibiciones de las autoridades civiles y eclesiásticas y su reiteración prueba que no se obedecían, pero además, en 1761, la necesidad de mano de obra en Castilla, obligó a permitir que allí pasasen las casadas o las solteras, hijas o hermanas de segadores ${ }^{56}$.

Sin embargo, esta migración dejó poco rastro en la documentación. Ellas hacían el viaje a pie desde Galicia a los campos de Castilla o seguían hacia Madrid -quinientos o seiscientos kilómetros- lo que a veces permite detectarlas en los registros de hospitales o parroquias de villas y ciudades de las zonas de paso. Por ejemplo, en el hospital de La Piedad de Benavente, lugar de tránsito de la ruta entre Galicia y la Meseta, en las muestras vaciadas por M. J. Pérez Álvarez a lo largo del siglo XviI, los gallegos registrados fueron muy numerosos -el 38,4\% del total, 910 personas- de los que el $7,7 \%$ (70), eran mujeres; el $65,2 \%$ eran solteras, $16,7 \%$ casadas y $18,2 \%$ viudas, mientras que ellos se repartían de un modo algo diferente, ya que apenas había viudos $(1,7 \%)$ y muchos $(32,8 \%)$ eran casados. Ellas procedían del rural pero al menos un 15,7\%, de ciudades -Santiago, Ferrol, Betanzos, Mondoñedo- y villas -Verín, Rianxo-. La mayoría, 34, había salido del área oriental de la actual provincia de Lugo -con una cierta concentración zonal en el área de Samos, por ejemplo- y 15 de la de Ourense, de modo que la Galicia occidental solo aparece un grupo

56. Sobrado Correa, H.: Las tierras de Lugo, p. 367; Meijide Pardo, A.: art. cit., pp. 532-534 y 599-600. Sobre estos problemas morales, REY CASTELAO, O.: «Las campesinas y el honor», cit. Artaza Montero, M. M. ${ }^{a}$ : «Los ilustrados gallegos y el problema de la emigración», Revista Galega do V Centenario, 7, 1990, pp. 185-202.

(C) Ediciones Universidad de Salamanca / ®@ Stud. his., H. ${ }^{a}$ mod., 38, n. 2 (2016), pp. 201-236 
OFELIA REY CASTELAO

CRISIS FAMILIARES Y MIGRACIONES EN LA GALICIA DEL SIGLO XVIII DESDE UNA PERSPECTIVA DE GÉNERO

significativo del entorno de Compostela (16) y raras veces de A Coruña o de Tui; es decir, son mujeres del interior oriental y noroeste ${ }^{57}$. Se han identificado gallegas en hospitales de Medina del Campo, Palencia, Talavera, etc. y en otros lugares de paso, se han localizado gallegas en las actas de matrimonio -La Bañeza, Torrejón de Ardoz, etc.- y en ciudades castellanas como Valladolid. No tenemos noticia de todas aquellas que se mantuvieron en áreas rurales durante sus estancias. En estos casos castellanos, se trataba de mujeres de la Galicia interior que no siempre volvieron a sus casas, en las que pocas perspectivas vitales les esperaban.

Pero sin duda, la opción preferida fue Madrid, no en vano requería servicio doméstico y mano de obra para trabajos eventuales y poco cualificados. Las gallegas eran numerosas ya desde el siglo XVII, trabajando como criadas, lavanderas, nodrizas, etc., reclutadas por agentes cuyas redes quizá se mantuvieron en el XVIII. En la capital, el 8,8\% de las inmigrantes eran de Galicia, solo superadas por las asturianas (9,9\%) y los gallegos eran el 11\% (12,7\% los asturianos). En realidad, el máximo se había producido a fines del XVII, cuando las gallegas eran el 27,2\% de las forasteras (9\% las asturianas) y la reducción drástica se data en 1704/13, cuando son solo el 3,2\% frente al 13\% de las asturianas; el 6,7\% en $1714 ; 7,7 \%$ en $1734 ; 8,2 \%$ en 1750 y $3,6 \%$ en $1780-99^{58}$. Es decir, la emigración no fue constante y quizá procediera de la Galicia oriental y noroeste, o al menos así era en el primer tramo del XIX. Esta migración plantea cuestiones laterales como la lingüística: la integración laboral podía verse complicada por el hecho de que su conocimiento del castellano era muy inferior al de los hombres, no tanto porque fueran analfabetas, que lo eran casi todas, sino porque al no haber sido escolarizadas, no tenían el contacto con el castellano que sus hermanos tenían a través de los maestros ${ }^{59}$.

Andalucía constituyó un destino preferente de los gallegos de ambos sexos en el siglo xviII, en especial en la segunda mitad, con un objetivo claro, los núcleos urbanos del área colonial, pero no único. Así, por ejemplo, en Granada, donde la inmigración gallega era la más numerosa en 1665 y 1730, desapareciendo desde 1780: un $19.5 \%$ de los contrayentes españoles eran gallegos (438) y en el XVIII el $23 \%$, y las gallegas eran $5.7 \%$; procedían del área compostelana $(83,4 \%)$, aportando

57. Pérez Álvarez, M. J.: «La hospitalidad en el norte de la Península Ibérica durante la Edad Moderna. La provincia de Zamora». Pérez Álverez, M. J. y Lobo, M. M. (Eds.): La respuesta social a la pobreza en la Península Ibérica durante la Edad Moderna. León, 2014, pp. 143-173. Agradezco a la autora los datos que figuran en el texto.

58. Carbajo Isla, M. F.: La población de la villa de Madrid: desde finales del siglo XVI, hasta mediados del siglo XIX. Madrid, 1987, pp. 119-122.

59. Deprez, Ch.: «Langues et migrations: dynamiques en cours», Linguistique, 41, 2, 2005, pp. 9-22; Rey Castelao, O.: «Diferencias e intercambios culturales entre el campo y la ciudad respecto de las mujeres en la España del siglo XVIII», Mundo Agrario, 27, 2013.

(C) Ediciones Universidad de Salamanca / ®@ Stud. his., H. ${ }^{a}$ mod., 38, n. 2 (2016), pp. 201-236 
OFELIA REY CASTELAO

CRISIS FAMILIARES Y MIGRACIONES EN LA GALICIA DEL SIGLO XVIII DESDE UNA PERSPECTIVA DE GÉNERO

pocos la Galicia interior (12,2\%) y menos la sudoccidental (4,4\% ${ }^{60}$. En Málaga, se registraron 23 galaicas antes de 1770, el 12,5\% de los inmigrantes de Galicia, sin que sepamos de dónde procedían ${ }^{61}$.

En el área colonial, Sevilla fue un destino importante para los gallegos, pero los estudios existentes se ciñen a las bodas celebradas en la parroquia de San Martín, donde los contrayentes gallegos eran entre el $4 \%$ y el 5,5\% desde mediados del XVI a 1800 , con un máximo en la primera mitad del xvis, cuando derivaron hacia Cádiz; antes de 1750, las gallegas que se casaron fueron pocas, 31, pero constituían una proporción importante de los inmigrantes galaicos -el $27,4 \%$ - y el $5,1 \%$ de las foráneas casadas allí, en su mayoría andaluzas. En la segunda mitad del xviII, aparecen solo diez, el 20\%, en evidente regresión, de modo que las gallegas solo son el 1,5\% de las inmigrantes ${ }^{62}$. Sin embargo, en 1800 , con todas las parroquias, se anotaron 26 gallegas y 272 gallegos, de forma que ellas eran el 9,5\% y ellos el $8,7 \%$ de los foráneos. Hombres y mujeres procedían de las mismas zonas, concentradas en el suroeste, en la antigua provincia de Tui, y una considerable proporción, eran originarios de ciudades y villas de esas zonas -Tui, Ponteareas, Baiona, A Guarda- y en general, localidades de la costa o de cerca de esta.

En el tras-país sevillano, en la villa de Utrera, situada en medio de una planicie cerealera, durante el xviI se casaron 1042 gallegos y 96 gallegas, el 8,46\%, en clara disminución en la segunda mitad del siglo, procedentes casi todas de la Galicia sudoccidental -el 73,3\% eran de la actual provincia de Pontevedra-, el 8\% de Coruña, $2,9 \%$ de Ourense y 1,9\% de Lugo, proporción similar a la de los hombres. Un dato importante es que el $85,4 \%$ de las gallegas que se casan en Utrera lo hacen con un hombre de fuera de esta localidad, como ellas ${ }^{63}$.

Los gallegos eran el sector más numeroso de los varones forasteros que se casaban en Cádiz y ahí fallecieron cerca de mil gallegos en el xviII: en las series de difuntos de la única parroquia de la ciudad aparecen 720 hombres y 259 mujeres, una cifra muy elevada con respecto a otros destinos, un $26,5 \%{ }^{64}$, pero los estudios existentes

60. Sanz Sampelayo, J.: Granada en el siglo XVIII. Granada, 1980, p. 392.

61. Sanz Sampelayo, J.: Factores de riesgo y de desarrollo en una ciudad del litoral andaluz: la población de Málaga en el siglo XVIII. Málaga, 1998, pp. 118-119.

62. Carmona, J. I.: Una aportación a la demografía de Sevilla en los siglos XVIII y XIX. Sevilla, 1976, p. 255; García-Baquero López, G.: Estudio demográfico de la parroquia de San Martín de Sevilla, 1551-1749. Sevilla, 1982, p. 174; Álvarez SanTalo, L. C.: La población de Sevilla en el primer tercio del siglo XIX. Sevilla, 1974, p. 254 y ss.

63. Del Pino Jiménez, A.: Demografía rural sevillana en el Antiguo Régimen: Utrera, Los Palacios-Villafranca y Dos Hermanas, 1600/1850. Sevilla, 2004, pp. 372 y 472.

64. PAscua, M. a J. de la: «Los Gallegos en el Cádiz de la carrera de indias, balance secular de un proceso migratorio (1682-1778)», en Eiras Roel, A. y Rey Castelao, O. (Eds.): Migraciones

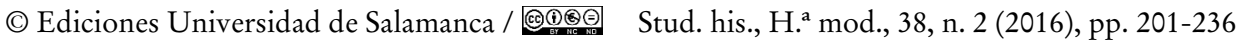


OFELIA REY CASTELAO

CRISIS FAMILIARES Y MIGRACIONES EN LA GALICIA DEL SIGLO XVIII DESDE UNA PERSPECTIVA DE GÉNERO

no dan el lugar de origen. En la misma área colonial, en el Puerto de Santa María hubo una abundante llegada de gallegos hasta 1764, disminuyendo luego, pero es una zona a donde llegaban muchos hombres casados, de origen rural y del suroeste de Galicia. Las actas de matrimonio registran 898 gallegos, el 13,6\% de los varones, y 56 gallegas, el 1,4\% de las casadas-. Más del sesenta por ciento procedía de la actual provincia de Pontevedra y en un eran de ciudades o de villas de la costa -5 de Coruña, 4 de Pontevedra, 8 de Vigo, 6 de Marín, y con un caso o dos de Padrón, Redondela, Poio- y no pocas de interior: 7 de Santiago, y también con uno o dos casos, Lugo, Portomarín, Monterrey, Meira, Villabol, lo que resulta muy significativo. Hay alguna diferencia con respecto a los hombres, ya que de la actual provincia de Pontevedra procedía el 51,2\%, 21,6\% de Coruña, 19,6\% de Lugo y 7,4\% de Ourense ${ }^{65}$.

En Portugal se ha comprobado la presencia de gallegas empleadas como domésticas en núcleos urbanos -Braga, Guimarâes, Porto-y en las zonas rurales de Entre-Douro y Minho. Portugal era un importantísimo destino de la emigración masculina, pero si los hombres estaban muy vigilados, no así las mujeres, y por esto mismo, hay poca información para calcular la cifra real de las emigradas. La bibliografía portuguesa ha atendido a los núcleos urbanos del litoral septentrional y en los últimos años C. Fernández Cortizo ${ }^{66}$ y D. L. González Lopo ${ }^{67}$ han reforzado esas aportaciones a partir de los registros de enfermos. En la Casa de Misericordia de Ponte do Lima, entre 1694 y 1750 las gallegas eran en torno al 5\% de los ingresados, oscilando los hombres entre el $9 \%$ en 1694/1704 y el 20,2\% en 1740/50; desde mediados del Xviı ellos se reducen al 9,7\% en 1751/75

internas, op. cit., pp. 719-731; «Gallegos y otras gentes del norte en Andalucía: la presencia gallega en Cádiz, 1682-1778», en Eiras Roel, A. y González Lopo, D. L.: Movilidad interna y migraciones intra-europeas en la Península Ibérica. Santiago de Compostela, 2002, pp. 55-77.

65. Iglesias Rodríguez, J. J.: Una ciudad mercantil en el siglo XviII. El Puerto de Sta. María. Sevilla, 1991, p. 137.

66. Fernández Cortizo, C. J.: «La emigración gallega al occidente de la región de EntreDouro-e-Minho, siglos Xiv-XIX», en Esteves, A. y Lobo De Araujo, M. M. (Eds.): Ponte de Lima: sociedade, economia e instituiçoes. Braga, 2012, pp. 83-106; «La emigración gallega ó Norte de Portugal (1700-1850), Revista do Noroeste, 1, 2006, 2, pp. 39-58; «Ir aos ganhos: a emigración galega ao norte de Portugal, 1700-1850», en Hernández Borge, J. y GonzÁlez Lopo, D. L: Pasado e presente, pp. 17-50; «A inmigración galega no Entre-Doiro-E-Minho de 1700 a 1850: condicións persoais e ocupacións profesionais dos emigrantes», Estudios Regionais, 4, 2010, pp. 13-34; Fernández Cortizo, C. y Sobrado Correa, H.: «Gallegos asistidos, gallegos encarcelados en el distrito de Porto, siglos XviII-XIX», en Lobo, M. M. y Pérez Álvarez, M. J.: Do Silêncio à Ribalta: os resgatados das marges da Historia. Séculos XVI-XIX. Braga, 2015, pp. 295-312.

67. GonzÁlez Lopo, D. L.: «La movilidad de la población portuguesa en el siglo XviII: la inmigración femenina en la capital del reino», en DUBERT, I. y SOBRADO, H.: El mar en los siglos modernos. Santiago de Compostela, 2009, pp. 85-100. Y «A presenza de galegos en Lisboa antes do terremoto (1745-17469», Pasado e presente..., pp. 51-84.

(C) Ediciones Universidad de Salamanca / ®@ Stud. his., H. ${ }^{a}$ mod., 38, n. 2 (2016), pp. 201-236 
y al $6,5 \%$ en $1776 / 99$, pero el descenso femenino fue mucho más acusado $-1,7 \%$ y $1,6 \%$ respectivamente-. En los hospitales de las Misericordias de Porto, las gallegas son el $11,3 \%$ de los gallegos ingresados en $1753 / 54$ y el $11,1 \%$ en 1793/94. A fines del xviII, en el de Vila Real, el 2,2\%; en el de Mesâo Frio el 6,8\%, solteras en su gran mayoría; y en San Marcos de Braga, en 1689/1712, se anotaron 26 de 51 ingresados. Finalmente, en Lisboa, en el Hospital de Todos-os-Santos y de Sâo José se anotaron 13 gallegas en 1715/16 (1,6\%), 43 en 1752 (3,9\%) y 17 en $1780(0,7 \%)$; el $33,8 \%$ eran solteras, $41,1 \%$ casadas y $20,5 \%$ viudas -se ignora las demás-, distribución diferente a los hombres $-73,7 \%$ solteros, $4,6 \%$ casados y pocos viudos-, y procedían el 32,2\% de Pontevedra, 30,8\% de Coruña, 19,1\% de Ourense y 7,3\% de Lugo y no se sabe las otras, en lo que también difieren de ellos, ya que Pontevedra aportaba el grueso $(61,5 \%$ ) y Ourense el $31,3 \%$, y las demás cifras muy inferiores; por otra parte, ellas tenían un notable origen urbano $\mathrm{y}$ costero. Conviene decir que raras veces aparecen gallegas en las actas matrimoniales: de hecho, solo en Âncora en 1740/1839 ellas son el 4,8\% de las novias «de fuera», donde en ese período eran el 6,8\% de las muertas foráneas -habían llegado a ser el 18,2\% en 1670-1739- y el 3\% en Barcelinhos de 1607 a 1800 . El origen es bastante diferente al que hemos visto en Castilla y se asemeja al de Andalucía.

Se podrían añadir otros desplazamientos que situaban a las gallegas entre las mujeres más móviles, pero todavía faltan datos. Su movilidad dependía, como la masculina, de las condiciones demográficas y socio-económicas de cada zona y de su papel en su grupo doméstico y en la comunidad: su actividad en la casa y en la explotación agraria, su lugar en la sucesión familiar y en la herencia, las posibilidades de casarse, de tener trabajo o de acceder a los bienes comunales, etc. Es decir, había una serie de elementos que inducían a irse en busca de otras opciones, frente a lo cual, las consideraciones morales jugaron un rol menor, como demuestra el hecho de que no se atendiera a las condenas sobre la participación en las migraciones temporeras; todo indica que viajaban parcialmente protegidas por hombres de sus familias, aunque el fraude en esto revela el grado de necesidad de las mujeres que se desplazaban a los destinos más lejanos. En los más cercanos, mantenían contacto con la familia y con la comunidad de origen, pero se perdía conforme la ausencia femenina se hacía más prolongada, eliminando la posibilidad de retorno cuando se había fracasado o se había alcanzado una edad avanzada.

La cronología de los datos expuestos revela que los destinos más lejanos recibieron menos gallegas en el último tramo del XviII, quizá por efecto del desarrollo de la proto-industria textil, que sirvió para retener a las mujeres -aunque también las obligaba a desplazamientos temporales para vender los productos-. En cuanto a las zonas, las gallegas emigraban dependiendo del sistema de herencia y de la relación que dentro de cada sistema tuvieran con los otros componentes

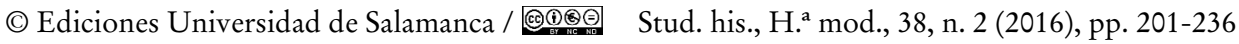


OFELIA REY CASTELAO

CRISIS FAMILIARES Y MIGRACIONES EN LA GALICIA DEL SIGLO XVIII DESDE UNA PERSPECTIVA DE GÉNERO

de la familia. Donde dominaba la familia de tipo troncal y la herencia prioritaria al hijo mayor -sobre todo en la provincia de Lugo-, sus hermanos y hermanas se quedaban en su compañía, trabajando en la tierra de la familia, ya que su parte de la herencia no les daba para casarse ni para vivir solos; si querían casarse, las mujeres tenían que buscar otros recursos y muchas iban a la siega con los hombres o se fueron a servir como criadas en Madrid. Donde predominaba el sistema de herencia de mejora corta y el reparto menos desigual y menos vinculado a un solo sexo, muchas mujeres vieron a sus maridos irse quedándose en una situación precaria; las que no lograban casarse solían vivir de modo independiente gracias a las tierras heredaras por vía de legítima, y la dedicación textil, pero estas mismas se iban a lejos -Andalucía, Portugal-: fue el caso de la Galicia del Sudoeste. Sabemos que la proto-industria permitió a muchas mujeres obtener recursos y evitar irse, pero, paradójicamente, les exigía movilidad, como se ha comprobado en otras zonas, en especial, en Bretaña o de Cataluña, y cuando la proto-industria entró en crisis, produjo emigración femenina ${ }^{68}$.

\section{A MODO DE CONCLUSIÓN}

La clave de lo que hemos tratado hasta aquí estaba en cuántas mujeres tenían que competir con los hombres en el reparto de la herencia y cuántas mujeres había de la misma edad al mismo tiempo compitiendo en el mercado nupcial y laboral en el contexto de una economía inelástica. Como hemos expuesto, en las zonas de emigración femenina a Castilla y a Madrid, el desequilibrio entre solteros y solteras era escaso -el 52,9\% en la provincia de Lugo, 23.758 solteras y 21.117 solteros de ese tramo de edad-y muy amplio en las zonas de emigración a Andalucía y a Portugal -el 59,3\% en la provincia de Tuy, 13.844 mujeres y 9.491 hombres-. El celibato definitivo y el retraso en la edad nupcial a los que estaban abocadas de forma casi general las mujeres no eran soluciones para sus «crisis» personales -es decir, aquellos momentos en que tuvieron que adoptar una decisión o alguien la tomó por ellas-, sino que eran síntomas de la insuficiencia de los recursos de las familias. Muchas de las solteras tuvieron que irse ellas mismas, a lugares muy distantes de sus casas, muriendo en hospitales de Lisboa o de Madrid, o, en el mejor de los casos, casándose en Utrera o en El Puerto de Santa María. De unas y de otras falta información, porque la pobreza deja menos rastros que la miseria. Las fuentes fragmentarias y parciales que se han podido utilizar en ausencia de otras que permitan una medición

68. Martín, J. y Pellerin, Y. (Eds.): Du lin à la toile: la protoindustrie textile en Bretagne. Rennes, 2008; Marfany, J.: Land, Proto-Industry and Population in Catalonia, c. 1680-1829. Surrey, 2012, pp. 89-124.

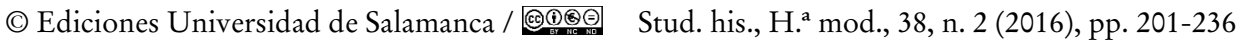


OFELIA REY CASTELAO

CRISIS FAMILIARES Y MIGRACIONES EN LA GALICIA DEL SIGLO XVIII DESDE UNA PERSPECTIVA DE GÉNERO

y algún cálculo global, detectan también bastantes casadas en el trasvase del campo a las villas y ciudades de Galicia y algunas en los desplazamientos fuera de Galicia; y aparece un cierto número de viudas, seguramente las más jóvenes, en las siegas de Castilla y no pocas como criadas en ciudades y villas gallegas, ya que las de más edad solían buscar acogida en los sistemas asistenciales urbanos. Pero eran las solteras las más numerosas y más arriesgadas en sus migraciones, si bien no de toda Galicia, sino de aquellos espacios donde había una migración masculina más intensa, que les servía de modelo y les daba una relativa protección.

Las mujeres casadas representaban la estabilidad en esas zonas migratorias, pero muchas de ellas vieron irse a sus maridos para buscar recursos o para huir de las deudas. En la Galicia oriental, el modelo migratorio masculino preferente era el estacional a Castilla, pero en la Galicia occidental, predominaban los desplazamientos a lugares muy distantes -Andalucía, Portugal, incluso América- y por períodos más largos -eran migraciones polianuales-, lo que aumentaba las posibilidades de que no volvieran, bien por voluntad propia, bien porque morían en el camino o en sus destinos. En estos casos, la ley castellana que se aplicaba en Galicia preveía los mecanismos mediante los cuales ellas podían vender bienes o acudir a la justicia, de modo que no quedaban legalmente desamparadas; esto se podría considerar positivo, como también el grado de independencia que estas mujeres lograban temporal o definitivamente. Pero si esta independencia era un «regalo envenenado» por cuanto suponía asumir mayor carga de trabajo, pagar las rentas y afrontar las responsabilidades de la economía familiar, se puede sospechar, además, que el interés de los acreedores en cobrar sus deudas, el de los rentistas por asegurar el cobro de rentas, y el de la monarquía, en percibir sus impuestos, estuvo detrás de la relativa facilidad con la que se dieron licencias para que las «viudas de vivos» actuasen en ausencia de sus cónyuges. Es una cuestión sobre la que seguir indagando, a sabiendas de que la documentación se resiste a informar de estos problemas.

\section{Bibliografía}

Álvarez Santalo, L.C.: La población de Sevilla en el primer tercio del siglo XIX. Sevilla, 1974.

Arango, J.: «Las "Leyes de las Migraciones” de E. G. Ravenstein, cien años después», Reis, 32, 1985.

Artaza Montero, M. M. ${ }^{\mathrm{a}}$ : «Los ilustrados gallegos y el problema de la emigración», Revista Galega do V Centenario, 7, 1989.

Barreiro Mallon, B. y Rey Castelao, O.: Pobres, enfermos y peregrinos. La red asistencial gallega en el Atiguo Régimen. Vigo, 1999.

Bodineau, P. y Lamarre, Ch. (Eds.): Capitales ou villes d'appui? Les petites villes et leurs campagnes du Môyen Âge au XxIe siècle. Dijon, 2014.

Carbajo Isla, M. F.: La población de la villa de Madrid: desde finales del siglo XVI, hasta mediados del siglo XIX. Madrid, 1987.

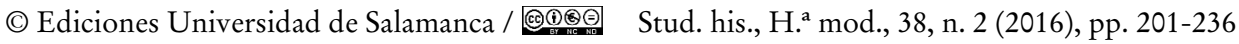


OFELIA REY CASTELAO

CRISIS FAMILIARES Y MIGRACIONES EN LA GALICIA DEL SIGLO XVIII DESDE UNA PERSPECTIVA DE GÉNERO

Carmona, J. I.: Una aportación a la demografía de Sevilla en los siglos XVIII y XIX. Sevilla, 1976.

Cebreiro Ares, F.: «Women and Credit in the Region of Santiago de Compostela at the End of Old Regime», Women and Credit in Preindustrial Europe, International Symposium, Universidad de Umea, 30-31/5/2016.

Dallera, C. y Ducret, V. (Eds.): Migration feminine. Au delá des stereotypes, s.l. 2004.

Del Pino Jiménez, A.: Demografía rural sevillana en el Antiguo Régimen: Utrera, Los Palacios-Villafranca y Dos Hermanas, 1600/1850. Sevilla, 2004.

Deprez, Ch.: «Langues et migrations: dynamiques en cours», Linguistique, 41, 2 2005.

Eiras Roel, A.: «A propos de la démographie urbaine d'Ancien Régime: l'exemple des petites villes de la Galice traditionnelle», en Historiens et Populations. Lovaina, 1991.

Eiras Roel, A.: «Para una comarcalización del estudio de la emigración gallega. La diversificación intrarregional a través de los censos de población», en Eiras Roel, A. (Ed.): Aportaciones al estudio de la emigración gallega. Un enfoque comarcal. Santiago de Compostela, 1992.

EIRAs Roel, A.: Estudios sobre agricultura y población en la España Moderna. Santiago de Compostela, 1990.

Fernández Cortizo, C. y Sobrado Correa, H.: «Gallegos asistidos, gallegos encarcelados en el distrito de Porto, siglos XVIII-XIX», en Lobo, M. M. y Pérez Álvarez, M. J. (Eds.): Do Silêncio à Ribalta: os resgatados das marges da Historia. Séculos XVI-XIX. Braga, 2015.

Fernández Cortizo, C. J.: «A inmigración galega no Entre-Doiro-E-Minho de 1700 a 1850: condicións persoais e ocupacións profesionais dos emigrantes», Estudios Regionais, 4, 2010.

Fernández Cortizo, C. J.: «Emigración peninsular y americana en Tierra de Montes (1700-1914», Revista Galega do V Centenario, 7, 1989.

FERnÁndez Cortizo, C. J.: «Ir aos ganhos: a emigración galega ao norte de Portugal, 17001850», en Hernández Borge, J. y González Lopo, D. L. (Eds.): Pasado e presente do fenómeno migratorio en Galicia. Santiago de Compostela, 2007.

Fernández Cortizo, C. J.: «La emigración gallega al occidente de la región de EntreDouro-e-Minho, siglos XIV-XIX», en Esteves, A. y Lobo de Araujo, M. M. (Eds.): Ponte de Lima: sociedade, economia e instituiçoes. Braga, 2012.

Fernández Cortizo, C. J.: «La emigración gallega ó Norte de Portugal (1700-1850)», Revista do Noroeste, 1, 2006, 2.

Fernández Cortizo, C. J.: «Trabajar por sus oficios fuera del Reino. El éxodo estacional en la Tierra de Montes, siglos XVII-XIX», en EIRAs Roel, A. (Ed.): Aportaciones al estudio de la emigración gallega. Un enfoque comarcal. Santiago de Compostela, 1992.

García GARCíA, M.: «La emigración en un sector de las Rías Bajas gallegas: el ejemplo de la Jurisdicción de Bayona, 1650-1800», en Eiras Roel, A. y Rey Castelao, O. (Eds.): Migraciones internas y medium-distance en la Peninsula Ibérica, 1500-1900. Santiago de Compostela, 1994.

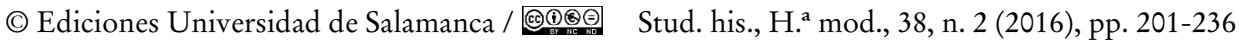


OFELIA REY CASTELAO

CRISIS FAMILIARES Y MIGRACIONES EN LA GALICIA DEL SIGLO XVIII DESDE UNA PERSPECTIVA DE GÉNERO

García GonzÁlez, F.: «Investigar la soledad: Mujeres solas, casa y trayectorias sociales en la Castilla rural del Antiguo Régimen», Obradoiro de Historia Moderna, 24, 2015.

García-Baquero López, G.: Estudio demográfico de la parroquia de San Martín de Sevilla, 1551-1749. Sevilla, 1982.

GonzÁlez de Ulloa, P.: Descripción de los Estados de la Casa de Monterrei en Galicia en el año 1777. Santiago de Compostela, 1950.

GonzÁlez Lopo, D. L.: «A presenza de galegos en Lisboa antes do terremoto (174517469", en Hernández Borje, J. y GonzÁlez Lopo, D. L. (Eds.): Pasado e presente do fenómeno migratorio en Galicia, Santiago de Compostela, 2007.

GonzÁlez Lopo, D. L.: «La movilidad de la población portuguesa en el siglo XviII: la inmigración femenina en la capital del reino», en Dubert, I. y Sobrado, H. (Eds.): El mar en los siglos modernos. Santiago de Compostela, 2009.

GonzÁlez Lopo, D. L.: «Una aproximación a la emigración de la Galicia occidental. Entre mediados del siglo XVIII y el primer tercio del siglo XX a través de las fuentes de protocolos y actas parroquiales», Revista galega do V Centenario, 6, 1988.

Grenier, B. y E. Charpentier, E. (Eds.): Femmes Face à L'absence, Bretagne et Québec (XVIIe-XVIIIe Siècles). Québec, 2015.

Iglesias Rodríguez, J. J.: Una ciudad mercantil en el siglo XVIII. El Puerto de Sta. María. Sevilla, 1991.

Jarnoux, Ph., Legallo, Y. y Roudot, F.: «Le port et sa ville au XViIIe siècle», en Legallo, Y. (Ed.): Histoire de Brest. Brest, 1976, p. 75.

JiméNEZ Julia, E.: «Una revisión crítica de las teorías migratorias desde la perspectiva de género», Arenal, 2, 1999, p. 239.

KAISER, T.: «Crisis? Wich crisis?Families and forced migration», en LindLeY, A. (Ed.): Crisis and Migration: Cultural Perspectives. Nueva York, 2014, s.p.

LeVY, A.: Brest et les brestois, 1720-1789. Brest, 1986.

Marfany, J.: Land, proto-industry and population in Catalonia, c. 1680-1829. Surrey, 2012.

Martín García, A.: «Prostitutas, pobres y expósitos. Marginados y excluidos en el Ferrol del Antiguo Régimen», Semata, 16, 2005.

Martín García, A.: Demografía y comportamientos demográficos en la Galicia moderna: la villa de Ferrol y su tierra, siglos XVI-XIX. León, 2005.

Martín, J. y Pellerin, Y. (Eds.): Du lin à la toile: la protoindustrie textile en Bretagne. Rennes, 2008.

Martínez Rodríguez, E., Burgo López, M. C., y GonzÁlez Lopo, D. L.: «Inmigración urbana en la Galicia del Antiguo Régimen, Santiago, Tuy y Ferrol a finales del siglo XVIII", en Eiras Roel, A. y Rey Castelao, O.: (Eds.): Migraciones internas y medium-distance en la Península Ibérica, 1500-1900. Santiago de Compostela, 1994.

Martínez Rodríguez, E.: La población de Santiago de Compostela, 1630-1860. Estructuras, coyunturas y comportamientos demográficos. Santiago de Compostela, 2015.

Maziane, L.: «Los cautivos europeos en Marruecos, siglos XVII-XVIII», en MarTínEz Torres, J. A. (Dir.): Circulación de personas e intercambios comerciales en el Mediterráneo y en el Atlántico, siglos XVI, XVII, XVIII. Madrid, 2008.

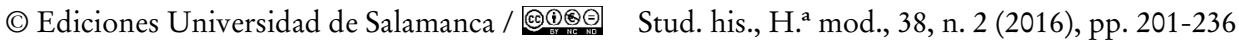


OFELIA REY CASTELAO

CRISIS FAMILIARES Y MIGRACIONES EN LA GALICIA DEL SIGLO XVIII DESDE UNA PERSPECTIVA DE GÉNERO

Meijide Pardo, A.: «La emigración gallega intra-peninsular en el siglo XVIII», Estudios de Historia Social de España, IV, 1960.

Pascua SÁnchez, M. J. de la: «Gallegos y otras gentes del norte en Andalucía: la presencia gallega en Cádiz, 1682-1778», en Eiras Roel, A. y GonzÁlez Lopo, D. L. (Eds.):Movilidad interna y migraciones intra-europeas en la Península Ibérica. Santiago de Compostela, 2002.

Pascua SÁnchez, M. J. Je la: «La cara oculta del sueño indiano: mujeres abandonadas en el Cádiz de la Carrera de Indias», Chronica Nova, 21, 1993-94.

Pascua Sánchez, M. ${ }^{a}$ J. de la: «Los Gallegos en el Cádiz de la Carrera de Indias, balance secular de un proceso migratorio (1682-1778)», en Eiras Roel, A. y Rey Castelao, O.: (Eds.): Migraciones internas y medium-distance en la Peninsula Ibérica, 15001900. Santiago de Compostela, 1994.

Pascua SÁnchez, M. J. de la: Mujeres solas: historias de amor y de abandono en el mundo hispánico. Málaga, 1998.

Pérez Álvarez, M. J.: «La hospitalidad en el norte de la Península Ibérica durante la Edad Moderna. La provincia de Zamora», en Pérez Álverez, M. J. y Lobo, M. M. (Eds.): La respuesta social a la pobreza en la Península Ibérica durante la Edad Moderna. León, 2014.

Pérez García, J. M.: «La intensa movilidad de la comarca del Bajo Miño y sus destinos», Minius. Historia, Arte e Xeografía, 19, 2011.

Perreon, St.: «Des soldats et des profits. L'impact de la consommation militaire dans les villes bretonnes au XVIIIe siècle», en BRAGARD, Ph. y otros (Eds.): L'armée et la ville dans l'Europe du Nord et du Nord-Ouest. Lovaina, 2006.

Poussou, J.P.: «La familia y los movimientos migratorios en Francia», en CHACÓN JIMÉNEZ, F. (Ed.): Familia y sociedad en el Mediterráneo occidental, siglos XV-XIX. Murcia, 1987.

Rey Castelao, O. y Barreiro Mallón, B.: «Apadrinar a un pobre en la diócesis de Santiago de Compostela, siglos XviI-XIX», en Pérez Álvarez, M. J. y Lobo, M. M. (Eds.): Las respuestas sociales a la pobreza en la Península Ibérica durante la Edad Moderna. León, 2014.

Rey Castelao, O. y Pérez Rodríguez, F.: «Movimientos migratorios en el municipio de A Cañiza, siglos XVII al XIX», en EIRAs Roel, A. (Ed.): Aportaciones al estudio de la emigración gallega. Un enfoque comarcal. Santiago de Compostela, 1992.

Rey Castelao, O. y Sobrado Correa, H.: «Fiscalidad y actividades económicas femeninas en las ciudades del Noroeste español a finales del Antiguo Régimen». XXVI Encontro da Ass. Portuguesa de $H^{a}$ Económica e Social. Ponta Delgada, 2006.

Rey Castelao, O.: «Les femmes seules du Nord-Ouest de l'Espagne: trajectoires féminines dans un territoire d'émigration, 1700-1860», Annales de démographie historique, 112, 2006, https://doi.org/10.3917/adh.112.0105.

Rey Castelao, O.: «L'effet des régimes démographiques et des systèmes familiaux sur la participation aux flux migratoires», en ORIS, M. (Ed.): Une démographie au féminin. Risques et opportunités dans le parcours de vie. Berna, 2009.

Rey Castelao, O.: «Diferencias e intercambios culturales entre el campo y la ciudad respecto de las mujeres en la España del siglo XVIII», Mundo Agrario, 27, 2013, s.p.

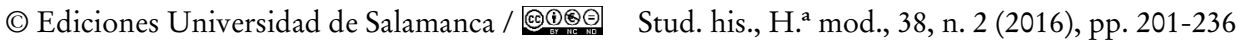


OFELIA REY CASTELAO

CRISIS FAMILIARES Y MIGRACIONES EN LA GALICIA DEL SIGLO XVIII DESDE UNA PERSPECTIVA DE GÉNERO

Rey Castelao, O.: «La emigración a América en la cuenca media del Ulla: un ejemplo de análisis comarcal», Revista Galega do Quinto Centenario, 4, 1990.

Rey Castelao, O.: «Galicia y Portugal en la Edad Moderna. Intercambios socioculturales», en Hernández Borge, J. y González Lopo, D. L. (Eds.): Pasado e presente do fenómeno migratorio en Galicia, Santiago de Compostela, 2007.

Rey Castelao, O.: «Las campesinas y el honor en la Galicia moderna», en Candau Chacón, M. ${ }^{a}$ L. (Ed.): Las mujeres y el honor en la Europa Moderna. Huelva, 2014.

Rey Castelao, O.: «Las migraciones de los rurales en el siglo XVIII: cuestiones pendientes», Minius, Historia, Arte e Xeografía, 20, 2012.

Rey Castelao, O.: «Las migraciones femeninas de Antiguo Régimen en su contexto europeo», en HernándeZ Borge, J. y GONZÁlez Lopo, D. L. (Eds.): Mujer y emigración, una perspectiva plural. Santiago de Compostela, 2008.

Rey Castelao, O.: «Las mujeres gallegas ante los tribunales: la defensa de lo suyo», Historia et Ius, 9, 2016.

Rey Castelao, O.: «Migraciones internas y medium-distance en Galicia, siglos XVI-XIX», en Eiras Roel, A. y Rey Castelao, O.: (Eds.): Migraciones internas y medium-distance en la Península Ibérica, 1500-1900. Santiago de Compostela, 1994.

Rial García, S.: «Las mujeres en el tribunal de la Real Audiencia de Galicia: una reflexión». II Coloquio Internacional AEIHM, Mujeres y ciudadanía, Santiago de Compostela, s.p.

Rial García, S.: «La actuación de las mujeres de ausentes en el comercio de bienes raíces en el entorno de la tierra de Santiago, 1700-1840»,en Eiras Roel, A. y Rey Castelao, O. (Eds.): Migraciones internas y medium-distance en la Peninsula Ibérica, 15001900. Santiago de Compostela, 1994.

Rial García, S.: Las mujeres en la economia urbana del Antiguo Régimen. Santiago durante el siglo XVIII. Sada, 1995.

Rial García, S.: Mujer y actividad económica en la Galicia Moderna. La inserción de las mujeres en la producción económica rural y urbana. Santiago de Compostela, 2003.

SaAvedra FernándeZ, P.: «Un aspecto de las crisis de subsistencia en la Galicia del Antiguo Régimen: las ventas de tierra», en Eiras Roel, A. (Ed.): La historia social de Galicia. Santiago de Compostela, 1981.

Sanz Sampelayo, J.: Factores de riesgo y de desarrollo en una ciudad del litoral andaluz: la población de Málaga en el siglo XVIII. Málaga, 1998.

SAnz Sampelayo, J.: Granada en el siglo XVIII. Granada, 1980.

Sobrado Correa, H.: La Ciudad de Lugo en el Antiguo Régimen: siglos XVI-XIX. Lugo, 2001.

Sobrado Correa, H.: Las tierras de Lugo en la Edad Moderna: economía campesina, familia y berencia, 1550-1860. La Coruña, 2001.

Tilves Diz, J.: «Las compraventas de tierras en la comarca compostelana en los siglos XVIIXVIII», en Eiras Roel, A. (Ed.): La Documentación Notarial y la Historia. Santiago de Compostela, 1984, p. 420.

Villán de la Fuente, O.: «Crisis agraria y transferencias de propiedad: el "gran invierno" de 1710 reflejado en las ventas de tierra», en EIRAs Roel, A. (Ed.): La historia social de Galicia. Santiago de Compostela, 1981, p. 193.

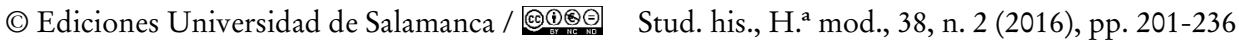

